\title{
Hydro ethanol extract of Holarrhena floribunda stem bark exhibits anti-anaphylactic and anti- oedematogenic effects in murine models of acute inflammation
}

\section{Stephen Antwi}

Kwame Nkrumah University of Science and Technology

Daniel Oduro-Mensah ( $\nabla$ danoduro-mensah@ug.edu.gh )

University of Ghana https://orcid.org/0000-0003-4492-2202

David Darko Obiri

Kwame Nkrumah University of Science and Technology

Newman Osafo

Kwame Nkrumah University of Science and Technology

\section{Aaron Opoku Antwi}

Kwame Nkrumah University of Science and Technology

\section{Helena Owusu Ansah}

Centre for Plant Medicine Research (CPMR)

\section{Augustine Ocloo}

University of Ghana

\section{Laud Okine}

University of Ghana

\section{Research Article}

Keywords: Anaphylaxis, COVID-19, Inflammation, Oedema, Prophylactic, Therapeutic

Posted Date: November 18th, 2020

DOl: https://doi.org/10.21203/rs.3.rs-110342/v1

License: (c) (1) This work is licensed under a Creative Commons Attribution 4.0 International License. Read Full License

Version of Record: A version of this preprint was published at BMC Complementary Medicine and Therapies on March 19th, 2022. See the published version at https://doi.org/10.1186/s12906-022-03565- 
6.

Page $2 / 40$ 


\section{Abstract}

Background: Holarrhena floribunda stem bark has anecdotal use in Ghanaian folk medicine for management of inflammatory conditions. This study was conducted to investigate the in vivo antiinflammatory activity of the bark extract using models of acute inflammation in male Sprague Dawley rats, C57BL/ 6 mice and 36 ICR mice.

Methods: A $70 \%$ hydro-ethanol extract of the stem bark (HFE) was evaluated at doses of $5-500 \mathrm{mg} / \mathrm{kg}$ bw. Local anaphylaxis was modelled by the pinnal cutaneous anaphylactic test. Systemic anaphylaxis or sepsis were modeled by compound $48 / 80$ or lipopolysaccharide, respectively. Clonidine-induced catalepsy was used to investigate effect on histamine signaling. Anti-oedematogenic effect was assessed by induction with carrageenan. Effects on mediators of biphasic acute inflammation were studied using histamine and serotonin (early phase) or prostaglandin E2 (late phase).

Results: HFE demonstrated anti-inflammatory and/or anti-oedematogenic activity comparable to standard doses of aspirin and diclofenac (inhibitors of cyclooxygenases-1 and -2), chlorpheniramine (histamine $\mathrm{H} 1$-receptor antagonist), dexamethasone (glucocorticoid receptor agonist), granisetron (serotonin receptor antagonist) and sodium cromoglycate (inhibitor of mast cell degranulation). All observed HFE bioactivities increased with dose.

Conclusions: The data provide evidence that the extract of $H$. floribunda stem bark has anti-anaphylactic and anti-oedematogenic effects; by interfering with signalling or metabolism of histamine, serotonin and prostaglandin $E_{2}$ which mediate progression of inflammation. The anti-inflammatory and antihistaminic activities of HFE may be relevant in the context of management of COVID-19.

\section{Background}

Inflammation serves as an immune response mechanism to rid the body of uncharacteristic stimuli due to invasion or injury. Several physiological pathways contribute to the immune inflammatory response. Dysfunction of the inflammatory response often leads to disability, organ malfunction, severe morbidity and even mortality if left untreated. Such dysregulation is what has been linked with fatality due to SARSCoV-2 infection, resulting from a cytokine storm and subsequent systemic hyper inflammation(Girija et al., 2020)(Song et al., 2020)(Ye et al., 2020). Even before COVID-19, inflammation-associated chronic disease conditions had been listed as the leading threat to human health (Pahwa \& Jialal, 2019)(Roth et al., 2018). Disease burden due to aberrant inflammation continues to increase, causing long-term morbidity and/or disability, and negatively affecting quality of life and economic well-being (Straub \& Schradin, 2016).

Anti-inflammatory agents used for treatment of inflammation-associated disease conditions include antihistamines, glucocorticoids, non-steroidal anti-inflammatory drugs, disease-modifying anti rheumatic 
drugs (DMARDs) and biologic drugs. These agents are used in different combinations for their distinct effects, a practice which highlights a significant challenge with management of inflammation-associated diseases - the fact that conventional anti-inflammatory agents typically have specific inflammation mediators as targets, leaving other uninhibited mediators to compensate. Furthermore, several of the agents have demonstrated significant toxicity in humans(Brown, 2009; de Nard et al., 2015; Laine et al., 2006; Lieberman et al., 2010; Minozzi et al., 2016). This makes them particularly unsuited for prophylactic or long-term use. There is the need to seek alternatives that have (1) potent activity, (2) non-toxicity to humans, particularly with prolonged use, and (3) ability to interact with multiple inflammatory response mediators.

Natural products, particularly from plant sources, continue to provide leads for development of medicinal compounds, including the majority of all medications in modern drug therapy (Atanasov et al., 2015; Cragg \& Newman, 2013; Pan et al., 2013; Thomford et al., 2018). Holarrhena floribunda is a shrub to medium-sized tree whose stem bark has popular anecdotal use in Ghanaian traditional settings for treatment of inflammation-related conditions. In other parts of West Africa, it is reported to be used medicinally as an anti-diabetic (Gnangoran et al., 2012), antibacterial and antifungal (Chukwurah, 1997) agent. This is the first in a series of three reports describing the anti-inflammatory bioactivity of the plant. Here, we describe the inhibitory effects of the hydro-ethanol extract of $H$. floribunda stem bark on acute inflammation. This study uses carrageenan/mediator-induced inflammation, and antigen-induced anaphylaxis, in murine models to highlight the broad-spectrum anti-inflammatory and antihistaminic activities of the plant part. Mediator-induced inflammation in rat and mouse models has predictive value for the assessment of anti-inflammatory agents that interact with inflammation mediators including histamine, bradykinin, serotonin, selected cytokines and tumor necrosis factor alpha (Crunkhorn \& Meacock, 1971; Morris, 2003; Salvemini et al., 1996; Vinegar et al., 1969). Also, striking similarities in the serology of antigen-induced anaphylaxis between humans and laboratory rat and mouse models have been shown (Lasselin et al., 2020; Strait et al., 2002).

\section{Methods}

\subsection{Chemicals and Reagents}

Compound 48/80, carrageenan, diclofenac, lipopolysaccharide (Escherichia coli 0127:B8 LPS), aspirin and dexamethasone were purchased from Sigma-Aldrich (St Louis, USA). Clonidine was purchased from Boehringer Ingelheim Inc (Ridgefield, USA), chlorpheniramine was from DWD Pharmaceuticals Ltd (Mumbai, India) and haloperidol rom from Incas Pharmaceuticals Pt. Ltd (Ahmedabad, India). Bovine serum albumen (BSA) was obtained from PAA Laboratories (Marburg, Germany). Sodium cromoglycate was purchased from Ashford Lab Pt. Ltd, (Mumbai, India), granisetron hydrochloride from Roche (Basel, Switzerland) and phosphate buffered saline (PBS) from Gibco (Karlsruhe, Germany). 


\subsection{Experimental animals}

The protocols for this study, including all animal experiments, were approved by the Ethics Committee of Centre for Plant Medicine Research, Mampong-Akuapem (approval number CPMR/M.6-PT3/2018). The animals were handled in accordance with internationally accepted principles of laboratory animal use and care (EEC Directive 2010/63/EU). A total of 216 male Sprague Dawley rats (SDR, 200-220 g), 36 C57BL/ 6 mice and 36 ICR mice (25-30 g) were obtained from and maintained at the Animal Experimentation Unit of Centre for Plant Medicine Research (CPMR), Mampong-Akuapem, Ghana. The animals were kept under ambient laboratory conditions: temperature $(28 \pm 2){ }^{\circ} \mathrm{C}$, relative humidity $60-70$ $\%$, and a normal light dark cycle of $12 \mathrm{~h}$. The animals were allowed access ad libitum to sterilized drinking water and powdered feed obtained from Ghana Agro Food Company (GAFCO), Tema. Animals were randomly assigned to groups labelled either as control (vehicle or positive) or extract treatment groups. Each group was housed in a metallic cage with dimensions $200 \mathrm{~cm} \times 252 \mathrm{~cm}^{2}$ for rats and 125 $\mathrm{cm} \times 65 \mathrm{~cm}^{2}$ for mice. Polyvinyl chloride plastic tubes and a plastic ball were provided in each cage as a source of environmental enrichment. All animals were acclimatized for seven days in the designated experimentation room before the start of experiments. The animals were trained to allow cooperation with restraint and other handling procedures. Animals in each single cage were considered as one experimental unit and received the same treatment. Drug/extract/vehicle was administered orally by gavage.

\subsection{Animal sampling and blinding}

The rats and mice were randomly assigned to groups using the randomization function on Microsoft Excel 2010. These groups were also randomly assigned to treatments in each experimental set. Each experimental set consisted of a total of 30 animals placed in 5 groups of 6 animals. The sample size that was used was calculated using the statistical software $G^{\star}$ power 3.1.9.2 with effect size of 0.85 , a probability of type one error of 0.05 , two tailed and a power of $80 \%$. All animals were kept in the same controlled room at the same level on metallic shelves. On treatment days, animals were dosed in random order with drug/extract/vehicle. Investigators and technicians responsible for experimental procedures were blinded. One scientist prepared drugs/extracts and assigned alphabetical designations. Another scientist administered drugs/extract/vehicle randomly to groups while a third scientist was responsible for observations and/or assessment of indices of interest. Statistical analyses were performed by a scientist who was blinded to the data groupings. 


\subsection{Humane endpoint and euthanasia}

The behavior of animals used in the experiments was monitored hourly for $12 \mathrm{~h}$ after administration of drug/extract, and then subsequently observed at 12-h intervals. Body condition scoring (Ullman-Culleré \& Foltz, 1999) was used to monitor the health of animals. Modifications of general and social behaviour were used as proxy to indicate animals in pain and distress. It was considered that animals that were not well groomed, with awkward gait, slightly hunched and/or agitated when touched were in distress. Animals were placed in social groups and trained before all experimental procedures. In all experiments where anaphylactic reactions and/or oedema were expected, and also where death of animals was necessary, humane endpoints were adopted to alleviate pain and distress, as well as euthanasia where necessary. The humane endpoints considered body temperature below $34{ }^{\circ} \mathrm{C}$, labored respiration evidenced by excessive abdominal involvement, reduced exploration, reduced grooming, inability to access food and water, and lack of response to manipulation (Franco et al., 2012; Ray et al., 2010). Euthanasia methods used were $800 \mathrm{mg} / \mathrm{kg}$ i.p. administration of pentobarbital sodium (Zatroch et al., 2017) in the case of rats and cervical dislocation in mice.

\subsection{Preparation of Hydro-ethanol Extract of $\boldsymbol{H}$. floribunda}

H. floribunda stem bark was obtained from the wild in Kwahu-Asakraka $\left(6^{\circ} 38 c 02.6^{2} \mathrm{~N} ; 0^{\circ} 41 \mathrm{c} 37.5^{2} \mathrm{~W}\right)$, Ghana. The plant part was collected, identified and authenticated by the Plant Development Department of CPMR. The Plant Development Department has a licence from the Forest Services Division of Forestry Commission of Ghana to source for plant material from the arboretum of CPMR and the wild. A specimen with voucher number 05/13 has been kept at the herbarium of CPMR. The material was washed, chopped into pieces, air-dried, and milled into a coarse powder. For extraction, $1 \mathrm{~kg}$ of powdered stem bark was macerated in $5 \mathrm{~L}$ ethanol $(70 \% \mathrm{v} / \mathrm{v})$ with periodic stirring, decanted after $72 \mathrm{~h}$ and filtered. Ethanol was removed by rotary evaporation (EYELA, Shanghai, China) and the aqueous concentrated extract was lyophilised to obtain powder with a yield of $7.33 \% \mathrm{w} / \mathrm{w}$. This was subsequently referred to as hydroethanol extract of $H$. floribunda (HFE). The lyophilate was reconstituted in normal saline $(0.9 \% \mathrm{w} / \mathrm{v} \mathrm{NaCl})$ for use in subsequent assays.

\subsection{Determination of Median Lethal Dose, $L_{50}$}

A single dose p.o. of $5000 \mathrm{mg} / \mathrm{kg}$ HFE was administered to SDRs $(\mathrm{n}=6)$ and ICR mice $(\mathrm{n}=6)$. The animals were observed over a 48-h period for general behaviour and euthanized at humane endpoints to prevent pain and distress. Animals surviving beyond $48 \mathrm{~h}$ were observed further over 12 days for signs of toxicity: piloerection, lachrymation, and difficulty with movement or breathing. 
Subsequently, five murine models of acute inflammation were used to investigate the in vivo antiinflammatory activity of HFE as described below.

\subsection{Anti-anaphylactic activity}

\subsubsection{Cutaneous anaphylaxis}

The pinnal inflammation model (Church et al., 1974) was adopted. Six groups $(n=6)$ of ICR mice were injected $s . c$ with $100 \mu \mathrm{l}$ of $0.05 \mathrm{mg} / \mathrm{ml} \mathrm{BSA}$ at start of the experiment, and again after 14 days with $100 \mu \mathrm{l}$ of $0.02 \mathrm{mg} / \mathrm{ml} \mathrm{BSA}$. On day 21 , test mice received p.o. $0.3 \mathrm{mg} / \mathrm{kg}$ dexamethasone, $100 \mathrm{mg} / \mathrm{kg}$ aspirin or HFE $(50,200$ or $500 \mathrm{mg} / \mathrm{kg})$, respectively, while control mice received $0.1 \mathrm{ml}$ normal saline. One hour after drug/extract administration, each mouse was put under isoflurane-induced anaesthesia (4 \%, drop jar method), $200 \mu \mathrm{l}$ Evans Blue dye ( $1 \% \mathrm{w} / \mathrm{v})$ was injected into the tail vein and both pinnae were immediately injected with $0.1 \mathrm{mg} / \mathrm{ml} \mathrm{BSA}$. Mice were euthanized $30 \mathrm{~min}$ later and their ears were cut off. Area of reaction was measured by circumscribing the area of extravasation of Evans blue dye and matching with the best fit of standard circles. Percentage inhibition of the inflammatory reaction was expressed as:

$\%$ Inhibition of reaction $=100 \times\left(\frac{A_{t}-A_{o}}{A_{o}}\right)$

Where $A_{o}$ and $A_{t}$ are the area of extravasation of dye in the pinnae of saline (vehicle) control or drug/extract-treated mice respectively.

\subsubsection{Compound 48/80-induced anaphylactic shock}

Anaphylactic shock was induced by compound 48/80 (Kim et al., 2005). C57BL/ 6 mice in 5 groups ( $\mathrm{n}=6$ ) received p.o. $10 \mathrm{ml} / \mathrm{kg}$ saline (vehicle), $50 \mathrm{mg} / \mathrm{kg}$ sodium cromoglycate or HFE (50, 200 or $500 \mathrm{mg} / \mathrm{kg}) 1$ $\mathrm{h}$ before administration of compound $48 / 80(8 \mathrm{mg} / \mathrm{kg}$, i.p.). Survival rate was monitored for $1 \mathrm{~h}$ post administration. Mice were euthanized at humane endpoints to prevent pain and distress and the time of euthanasia was used as the end point of the experiment. 


\subsubsection{Lipopolysaccharide-induced anaphylaxis}

Systemic anaphylaxis was induced by LPS administration (Lowry, 2005). Groups of SDRs $(n=6)$ were challenged i.p. with $5 \mathrm{mg} / \mathrm{kg}$ LPS in saline at $10 \mathrm{ml} / \mathrm{kg}$ bw. In the prophylactic model, treatment was administered twice; $24 \mathrm{~h}$ and $1 \mathrm{~h}$ before LPS challenge. In the therapeutic model, treatment was only administered $1 \mathrm{~h}$ after LPS challenge. Treatment agents were administered i.p.: $10 \mathrm{ml} / \mathrm{kg}$ saline, 0.3 $\mathrm{mg} / \mathrm{kg}$ dexamethasone or HFE (50, 200 or $500 \mathrm{mg} / \mathrm{kg})$. Survival rate was monitored for $168 \mathrm{~h}$ after LPS challenge. Rats were euthanized at humane endpoints to prevent pain and distress and the time of euthanasia was used as the end point of the experiment.

\subsubsection{Membrane stabilisation assay}

Whole blood was collected from rats under $4 \%$ isoflurane anaesthesia into heparinised vacutainer tubes (Thomas Scientific, Swedesboro, NJ). The blood was washed (3000 rpm for $10 \mathrm{mins}$ ) three times with $0.9 \%$ saline and reconstituted as a $40 \% \mathrm{v} / \mathrm{v}$ suspension with isotonic buffer ( $10 \mathrm{mM}$ sodium phosphate buffer with $0.9 \% \mathrm{NaCl}$ ) at $\mathrm{pH}$ 7.4. Protection of red blood cells from heat-induced hemolysis was assessed as described by (Abe et al., 1991; Shinde et al., 1999). Absorbance measurements were taken at $540 \mathrm{~nm}$ using Shimadzu UV-160A spectrophotometer. Acetyl salicylic acid (ASA) $200 \mu \mathrm{g} / \mathrm{ml}$ was used as a reference standard. Percent inhibition of hemolysis was calculated as:

$\%$ Inhibition of hemolysis $=100 \times\left(1-\frac{O D_{2}-O D_{1}}{O D_{\mathrm{z}}-O D_{1}}\right)$

Where $\mathrm{OD}_{1}, \mathrm{OD}_{2}$ and $\mathrm{OD}_{3}$ are absorbance readings for unheated test sample, heated test sample and heated control sample, respectively.

\subsubsection{Clonidine-induced catalepsy}

Indirect antihistaminic activity was investigated (Ferré et al., 1990). Groups of ICR mice $(n=6)$ were treated p.o. with $10 \mathrm{ml} / \mathrm{kg}$ saline, $4 \mathrm{mg} / \mathrm{kg}$ chlorpheniramine or HFE (50, 200 or $500 \mathrm{mg} / \mathrm{kg})$. In the prophylactic protocol, control drug or extract was administered $1 \mathrm{~h}$ prior to catalepsy induction while in the therapeutic protocol, drug or extract was administered $1 \mathrm{~h}$ post induction. Animals received $5 \mathrm{mg} / \mathrm{kg}$ clonidine s.c. and were made to grip a horizontal bar $(1 \mathrm{~cm}$ diameter, $3 \mathrm{~cm}$ high) with their fore paws. The time taken to let go was recorded as duration of catalepsy, measured at 30 min interval for $3 \mathrm{~h}$ after catalepsy induction. Maximal cataleptic effect was estimated by change in catalepsy calculated as: Treated mice were euthanized at humane endpoints to prevent pain and distress 
$\%$ Change in catalepsy $=100 \times\left(\frac{\text { Catalepsy }\left(T_{t}\right)-\operatorname{Catalepsy}\left(T_{0}\right)}{\operatorname{Catalepsy}\left(T_{0}\right)}\right)$

Where $T_{t}$ and $T_{0}$ are catalepsy at a time point of measurement and catalepsy at baseline, respectively.

Total catalepsy induced was measured as area under the time course curve (AUC).

\subsection{Anti-inflammatory Activity: Paw Oedema in Mice}

Paw oedema was induced in groups $(n=6)$ of SDRs by sub-plantar injection of $100 \mu$ l of a phlogistic agent (1\% w/v) in the right hind paw (Winter et al., 1962); (Singh \& Pandey, 1996). Phlogistic agents used were carrageenan, histamine, serotonin or prostaglandin $E_{2}$, all freshly prepared in normal saline. In the prophylactic protocol, $10 \mathrm{ml} / \mathrm{kg}$ saline, $4 \mathrm{mg} / \mathrm{kg}$ chlorpheniramine, $100 \mu \mathrm{g} / \mathrm{kg}$ granisetron, $100 \mathrm{mg} / \mathrm{kg}$ diclofenac or HFE $(50,200$ or $500 \mathrm{mg} / \mathrm{kg})$ were administered p.o. before injection of the phlogistic agent (carrageenan, histamine, serotonin or prostaglandin $E_{2}$ ). In the therapeutic protocol, control drug or extract was given $1 \mathrm{~h}$ after injection of the phlogistic agent (carrageenan). Paw volumes were measured by a plethysmometer at $1 \mathrm{~h}$ intervals for $4 \mathrm{~h}$. Raw measures for paw volume were normalised as percentage change from the baseline value. Maximal oedema response was calculated as:

$\%$ Increase in paw volume $=100 \times\left(\frac{p v_{t}-p v_{0}}{p v_{0}}\right)$

Where $p v_{(\mathrm{t})}$ and $p v_{(0)}$ are paw volume at a point of measurement and at baseline, respectively.

Total oedema induced over the $4 \mathrm{~h}$ period was measured as area under the time course curves (AUC).

\subsection{Statistical Analyses}

Data were analysed by one-way analysis of variance (ANOVA), followed by Dunnett's multiple comparison post hoc test on GraphPad Prism for Windows Version 5.00 (GraphPad, San Diego, CA). Data are expressed as mean \pm standard error of mean. Survival curves were analysed by Log-rank (Mantel Cox) test. All data from experimental units were included in data analysis. Each analysis reported had 6 values of specific outcome parameters obtained from 6 animals in an experimental unit. 


\section{Results}

\subsection{L $\quad \mathrm{LD}_{50}$ of HFE}

No mortality was recorded within $48 \mathrm{~h}$ after administration of a single oral dose of HFE ( $5000 \mathrm{mg} / \mathrm{kg} \mathrm{bw})$. There were no physical signs of toxicity, as evidenced by normal locomotory and respiratory activity. No lachrymatory effect, bulging of eyes or piloerection was observed.

\subsection{Anti-anaphylactic Activity of HFE}

\subsubsection{Cutaneous anaphylaxis}

Pinnal challenge with BSA in previously sensitized mice induced local inflammation marked by extravasation of Evans blue dye. Mean reaction area for the saline-treated control was $40.25 \pm 4.52 \mathrm{~mm}^{2}$ (Fig. 1). HFE reduced area of extravasation to $6.77-22.26 \mathrm{~mm}^{2}(P \leq 0.013)$. The reduction by $500 \mathrm{mg} / \mathrm{kg}$ HFE was comparable $(P \geq 0.809)$ to the values for dexamethasone $\left(7.85 \mathrm{~mm}^{2}\right)$ and aspirin $\left(5.75 \mathrm{~mm}^{2}\right)$.

\subsubsection{Compound 48/80-induced shock}

Compound $48 / 80$ caused $100 \%$ mortality within 25 min of administration in all saline-treated control mice (Fig. 2). Survival proportion for sodium cromoglycate was $50 \%$ over $60 \mathrm{~min}$. HFE protected mice, evidenced by the survival proportions increasing from $0(50 \mathrm{mg} / \mathrm{kg})$ to 16 or $50 \%$ for the 200 or 500 $\mathrm{mg} / \mathrm{kg}$ groups, respectively.

\subsubsection{Lipopolysaccharide-induced systemic anaphylaxis}

In sepsis modelled by LPS-induced anaphylaxis, $100 \%$ mortality was observed among saline-treated control mice 10-12 hours after LPS challenge. In the prophylactic model, drug/extract-treated rats survived beyond $12 \mathrm{~h}$ (Fig. 3A). Dexamethasone failed to protect beyond $24 \mathrm{~h}$ whereas survival proportion for all HFE-treated groups was $20 \%$. Therapeutic HFE administration protected rats, with survival proportions of 0,20 or $40 \%$ for the 50,200 or $500 \mathrm{mg} / \mathrm{kg}$ groups, respectively (Fig 3B). Survival for therapeutic dexamethasone was $60 \%$. 


\subsection{Membrane stabilisation assay}

HFE protected rat erythrocyte membrane from heat-induced lysis (Fig 4). HFE at $200 \mathrm{mg} / \mathrm{ml}$ had activity comparable to $200 \mu \mathrm{g} / \mathrm{ml}$ acetylsalicylic acid (reference drug), whereas $500 \mathrm{mg} / \mathrm{ml} \mathrm{HFE} \mathrm{had}$ approximately twice the activity of the reference.

\subsection{Clonidine- and haloperidol-induced catalepsy}

Relative to the saline-treated control $(31.4 \pm 8.1 \mathrm{~s})$, prophylactic HFE reduced maximum duration of clonidine-induced catalepsy to 4.8-6.8 s, $P \leq 0.001$ (Fig. 5A). Total catalepsy was also reduced to $15.8-$ $24.4 \%(P \leq 0.002)$ of the control value (Fig. 5B). Therapeutic administration of HFE reduced maximum duration of clonidine-induced catalepsy from the control value of $19.0 \pm 4.5 \mathrm{~s}$ to $6.2-8.5 \mathrm{~s}, P \leq 0.047$ (Fig. 5C). Again, total catalepsy was reduced to $29.8-38.5 \%(P \leq 0.044)$ of the control value (Fig. 5D).

\subsection{HFE anti-oedematogenic activity}

\subsubsection{Carrageenan-induced paw oedema}

Paw oedema peaked between $2-3 \mathrm{~h}$ in control rats (Figs 6.1 A and 6.1 C). In the prophylactic model, percentage mean maximal oedema for the saline-treated control group was $67.7 \pm 9.1 \%$ of baseline value (Fig. 6.1 A). HFE caused reductions to 33.4-46.6\%, which were significant $(P \leq 0.0015)$ for the 200 and $500 \mathrm{mg} / \mathrm{kg}$ doses. Maximal oedema for diclofenac was $6.29 \%$ of baseline value, and total paw oedema over the $4 \mathrm{~h}$ period was reduced to $10.9 \%$ of the control value (Fig $6.1 \mathrm{~B}$ ). Reduction of oedema by HFE was significantly different $(P \leq 0.02)$ from the control only for the $200(39.0 \%)$ and $500 \mathrm{mg} / \mathrm{kg}$ (34.6\%) doses.

On therapeutic administration, percentage mean maximal oedema for the inflamed control group was $59.2 \pm 7.6 \%$ of baseline (Fig. $6.1 \mathrm{C}$ ). HFE reduced the mean maximal oedema to $31.2-42.6 \%(P \leq 0.04)$. Total paw oedema over the $4 \mathrm{~h}$ period was reduced to $43.4-66.6 \%$ of the control value (Fig $6.1 \mathrm{D})$. Reduction by 200 and $500 \mathrm{mg} / \mathrm{kg} \mathrm{HFE}$ were different $(P \leq 0.004)$ from the inflamed control value and were comparable $(P \geq 0.99)$ to reduction by diclofenac. 


\subsubsection{Mediator-induced oedema}

Percentage mean maximal histamine-induced oedema for the saline-treated control was $70.9 \pm 4.5 \%$ of baseline (Fig. 7A). HFE caused a reduction to $46.9-54.5 \%$. Total paw oedema was reduced to 65.1-77.9 $\%$ of the inflamed control (Fig 7B), significant only for 200 and $500 \mathrm{mg} / \mathrm{kg} \mathrm{HFE} \mathrm{(} P \leq 0.022$ ). Inhibition of total oedema by chlorpheniramine $(64.9 \%)$ was not significantly different $(P \geq 0.54)$ from inhibition by HFE.

Maximal oedema due to serotonin was $59.2 \pm 8.08 \%$ for the control group. HFE reduced the percentage mean maximal oedema to $15.8-28.2 \%(P \leq 0.003)$ of baseline value (Fig. $7 C)$. Total paw oedema was also reduced to $19.2-48.9 \%(P \leq 0.003)$ of the control value (Fig 7D). Inhibition of oedema by HFE was not different $(P \geq 0.38)$ from inhibition by granisetron $(27.3 \%)$.

Prostaglandin $E_{2}$ produced mean maximal oedema $75.4 \pm 1.5 \%$ of the baseline value, which was reduced by HFE to $16.5-32.8 \%, P \leq 0.001$ (Fig. 7E). Total paw oedema also reduced to $21.6-45.6 \%(P \leq 0.001)$ of the control value (Fig 7F). Inhibition by diclofenac (10.1\%) was not different $(P \geq 0.15)$ from inhibition by 200 and $500 \mathrm{mg} / \mathrm{kg} \mathrm{HFE}$.

\subsection{Discussion}

This report highlights the broad-spectrum anti-inflammatory activity of the hydroethanolic extract of $H$. floribunda stem bark (HFE). Different rodent models were used to represent anaphylaxis and oedema due to distinct mechanisms of immune inflammatory response. In the cutaneous anaphylaxis design used in this study, the local allergic response to BSA is thought to be a type I hypersensitivity response induced mainly by vasoactive and pro-inflammatory mediators, primarily histamine released from mast cells and basophils (Waalkes \& Coburn, 1960)(White, 1990)(Evans et al., 2014)(Bryce et al., 2016). Like localized anaphylaxis, systemic anaphylaxis due to LPS and compound 48/80 are also mediated through degranulation of mast cells (Chatterjea et al., 2012; Ennis et al., 1980; Juskewitch et al., 2012; Lee et al., 2017), followed by perturbation of the membrane of other immune cells which allows inflammation mediators to leak out into circulation (Tasaka et al., 1986). HFE reduced cutaneous anaphylaxis (Fig. 1), and protected mice from mortality due to shock or systemic anaphylaxis from compound 48/80 (Fig. 2) or LPS (Fig. 3). Upon challenge with compound $48 / 80$ which is potent at causing mast cell degranulation (Ennis et al., 1980; Schemann et al., 2012; Tasaka et al., 1986), HFE at $500 \mathrm{mg} / \mathrm{kg}$ offered better protection than sodium cromoglycate $(50 \mathrm{mg} / \mathrm{kg}$ ) in terms of survival duration (Fig. 2), and was observed to delay onset of symptoms of shock and anaphylaxis. Together, these suggest that HFE may either be 
acting as (1) a mast cell membrane stabilizer, similar to sodium cromoglycate, to inhibit release of inflammation mediators and/or (2) an antagonist of histamine and/or other inflammation mediators released after mast cell degranulation.

LPS-induced anaphylaxis is mediated in its early stages by cytokines, including IL-1a, IL-6 and IL-10, all of which have short half-lives (Qiao et al., 2006; Reimann et al., 1994; Shapira et al., 1996). This is followed by stimulation of mast cell degranulation after approximately $6 \mathrm{~h}$ of challenge (Yang et al., 2012). Data from this anaphylaxis model (Fig. 3) gave indication of the ability of HFE to interact with the indicated cytokines and added to the evidence of HFE interaction with mediators released from mast cells. Mediators released from mast cells are critical to anaphylactic shock, possibly explaining why mortality was not recorded in this experiment until after the 6th hour of LPS challenge (Fig. 3a \& b). Whereas therapeutic administration of dexamethasone offered the highest level of protection up to $48 \mathrm{~h}$, relative to the HFE doses, prophylactic administration (Fig. 3a) failed to protect beyond $24 \mathrm{~h}$. Prophylactic administration of HFE afforded better protection than dexamethasone in terms of duration of survival throughout the $48 \mathrm{~h}$ observation period, as well as overall survival rate. When administered $1 \mathrm{~h}$ prior to challenge in the prophylactic model, blood dexamethasone levels may have peaked and began to drop even before LPS challenge, leaving less than the concentrations required for protective inhibition of expression/release of inflammation mediators (Perez et al., 1998; Savard et al., 2009). In the therapeutic model (Fig 3b), blood dexamethasone levels would have peaked approximately 90 min after challenge. Therefore, cytokine involvement may already have occurred by the time the treatment agent was introduced, and the inflammatory response would have started shifting toward mediator synthesis and degranulation. Dexamethasone is known to strongly inhibit histamine synthesis (N Hirasawa et al., 2001; Noriyasu Hirasawa, 2019). This may explain the high rate of protection seen with dexamethasone in the therapeutic model but not the prophylactic. The low levels of dexamethasone available after challenge in the prophylactic model may not have interfered enough with the early stage cytokine activity or inhibited histamine synthesis enough to protect significantly from events post challenge. Unlike dexamethasone, any clearance of drug/extract that may have occurred did not significantly affect the protective effect of HFE in prophylactic administration since survival rate was the same for all HFE prophylactic doses. Protection due to therapeutic administration of HFE (200 and $500 \mathrm{mg} / \mathrm{kg}$ ) was not significantly different ( $p=0.5356$ and 0.1740 , respectively) from that of dexamethasone. It has been demonstrated in a rat model that pharmacodynamics of dexamethasone is not different between arthritic and healthy rats (Earp et al., 2008). Therefore, the dynamics of protection offered by dexamethasone in this study is unlikely to be attributable to adjusted physiology in the arthritic state.

Anti-inflammatory agents may act to inhibit release of mediators, including histamine, from proinflammatory cells. This is achieved by causing increase in the surface area volume ratio of cells through expansion of the membrane, shrinkage of the cell, interacting with membrane proteins or altering 
influx of calcium into the cells (Ennis et al., 1980; Kelmenson et al., 2013; Pearce, 1985). In the membrane protection/stabilization assay, HFE demonstrated activity comparable to an equal concentration of acetyl salicylic acid (Fig. 4). This suggests that HFE has potent membrane-stabilizing activity and may be capable of interfering with mast cell degranulation.

Ability of HFE to affect histamine metabolism is again indicated by the reduction in catalepsy observed upon HFE administration in clonidine-induced catalepsy (Fig. 5a-d). Unlike other catalepsy-inducing agents such as haloperidol (Sanberg, 1980), clonidine stimulates histamine release from mast cells, in a manner similar to compound 48/80 (Lakdawala et al., 1980; Stanworth, 1973). The various stages of clonidine-induced catalepsy have been established to parallel brain levels of histamine (Chopra \& Dandiya, 1975), and the catalepsy may be inhibited by histamine receptor 1 (H1R) but not H2R antagonists (Jadhav et al., 1983; Lakdawala et al., 1980). Again, mediator-induced edema due to histamine was inhibited by HFE (Fig. 7a), further demonstrating the interaction between HFE and histamine metabolism. It was expected that HFE effect on histamine-induced oedema would be stronger than was observed in this study. The moderate inhibition of oedema, however, supports the thinking that HFE effect on histamine metabolism may not only be post-degranulation but may involve suppression of mediator expression.

Taken together, the strong HFE inhibitory activity on LPS-induced anaphylaxis, the strong membranestabilizing activity and data from the histamine-induced oedema experiment suggest that (1) HFE may interact with mediators of early stage LPS-induced anaphylaxis, such as IL-1 $\beta$, tumor necrosis factor alpha (TNF-a) and IL-6; (2) even if HFE does not inhibit histamine synthesis, it is be capable of inhibiting mast cell degranulation by membrane-stabilizing activity; and (3) HFE may be interfering with histamine signaling pre and post degranulation, and interacting with histamine receptors including H4R which has been shown to be a mediator in LPS-induced inflammation (Cowden et al., 2010). In addition, we note that before the $24 \mathrm{~h}$ time point, even the lowest prophylactic HFE dose offered better protection from LPS than dexamethasone, indicating better suitability for prophylactic use. These properties make HFE a potential candidate for use in management of COVID-19-associated inflammation. Among other cytokines and inflammation mediators, IL-1, -6, TNF- $a$ and histamine have been strongly linked to COVID19 severity and associated mortality (Huang et al., 2020; Malone et al., 2020; Ruan et al., 2020)(Zhang et al., 2020). Histamine plays a central role in acute inflammation and anaphylaxis (Branco et al., 2018) (Winbery \& Lieberman, 2002). Relevant to COVID-19, histamine release from mast cells is known to mediate bronchoconstriction (Barnes, 1991; Hill, 1992; Kilinc et al., 2020; Kritas et al., 2020), and has been implicated in the progression of oedema observed in COVID-19 pulmonary disease (Malone et al., 2020). Further supporting evidence of the primary role of histamine in COVID-19 progression include early symptoms such as anosmia, ageusia, skin rashes, neuropsychiatric symptoms, silent hypoxia and cachexia, all of which are consistent with dysfunctional histamine signaling (Becker et al., 2012; Lechien 
et al., 2020; Zwickl et al., 2019). In Ghana, the most common symptoms include cough, headache, sore throat, myalgia and anorexia (E. Oduro-Mensah, personal communication, August 14, 2020), also linked to elevated histamine levels. Interfering with histamine signaling after virus infection may provide a means to inhibit progression of disease, and modulate the immune response to prevent mortality or severe morbidity from hyperinflammation (Geurdes, 2020). In addition, the use of antihistamines can help reduce SARS-CoV-2 transmission through droplets since antihistamines may suppress symptoms such as sneezing and coughing (Aydin \& Aydin, 2020). With its demonstrated antihistamine activity, prophylactic or therapeutic HFE administration may contribute to inhibition of disease progression after SARS-CoV-2 infection and reduction of spread. This would be particularly useful in a low-income country like Ghana where most people already depend on plant-based remedies for management, treatment and/or prevention of disease, including COVID-19.

Progression of oedema after administration of carrageenan is a biphasic event. In this study, however, only the initial acute phase (Posadas et al., 2004) whose mediators include histamine, serotonin, kinins, leukotrienes, cytokines and inducible cyclooxygenase (COX)-2 (Crunkhorn \& Meacock, 1971; Gupta et al., 2006; Hwang et al., 1996; Lo et al., 1987; Nantel et al., 1999; Vinegar et al., 1969) was monitored.

Diclofenac which was used as the reference agent is considered a broad-spectrum NSAID with multiple modes of action (Gan, 2010), and is known to be a strong inhibitor of COX-1 and -2 among others (Scholer et al., 1986; Voilley et al., 2001). The anti-inflammatory effect of HFE is evident from the oedema suppression in both the prophylactic and therapeutic models. Diclofenac administration as a prophylactic agent inhibited oedema by approximately $90 \%$ whereas HFE inhibited by up to $65 \%$ (Fig. 6a). In the therapeutic model, maximum oedema inhibition by HFE was similar to inhibition by diclofenac (48 \%) (Fig. 6b). Also, HFE strongly inhibited edema due to serotonin (Fig. 7b) and prostaglandin E2 (Fig. 7c), demonstrating its ability to interact with multiple inflammation mediators released from immune cells.

In this study, HFE has demonstrated both prophylactic and therapeutic anti-inflammatory effects. Particularly in relation to carrageenan-induced inflammation, this is significant due to a number of previous paradoxical observations indicating that prophylactic inflammation inhibitory effect of an agent does not necessarily imply therapeutic effect and vice versa (Kaibara et al., 1983; Larsson et al., 1990). This study was limited to the use of different rodent models to represent anaphylaxis and oedema due to distinct mechanisms of immune inflammatory response in humans. Though the models provide useful information with regards to the effects of HFE on acute inflammation and anaphylaxis, the results may not directly mimic effects in other animal species or human inflammatory disease (Burkhardt \& Zlotnik, 2013; Seok et al., 2013). Predictions about human health will, therefore, require validation through further experimentation and/or clinical trials. 
Based on our data, the observed HFE antihistaminic activities are expected to be mediated in part through interaction with the H1R and H4R receptors, both of which play important roles in the progression and modulation of histamine-mediated conditions (Jemima et al., 2014; Ohsawa \& Hirasawa, 2014; Thangam et al., 2018). It is considered also that the absence of acute toxicity at $5000 \mathrm{mg} / \mathrm{kg}$ bw adds to the evidence for usefulness of HFE. Further, having both prophylactic and therapeutic inhibitory activities suggests that HFE is capable of interaction with other key mediators of mechanisms that underlie different pathways of inflammation development. Specific investigations into HFE interaction with signalling intermediates pertinent to modulation of the inflammatory response, including relevance to COVID-19, are warranted. Some anti-inflammatory agents, including dexamethasone, hydroxychloroquine and famotidine, have shown utility in COVID-19 management. Famotidine is an anti-inflammatory antihistamine whose usefulness against COVID-19 is evidently not achieved by antiviral activity (Freedberg et al., 2020; Malone et al., 2020) Hydroxychloroquine on the other hand is a DMARD whose usefulness in COVID-19 management is suggested to be both anti-inflammatory and antiviral (Liu et al., 2020; Ornstein \& Sperber, 1996).

\section{Conclusion}

HFE has broad-spectrum anti-inflammatory activity, as seen by its comparable activity to the several agents used as standards in this study. The data provide evidence that HFE has anti-anaphylactic and anti-oedematogenic effects: possibly through interference with histamine, serotonin and prostaglandin $E_{2}$ signalling, as well as interaction with several other factors which mediate development and progression of inflammation. Inquiry to elucidate the mechanism(s) of action of HFE is warranted.

\section{Abbreviations}

HFE

DMARDs

BSA

PBS

SDR

CPMR

GAFCO

ASA

$\mathrm{HR}$
Holarrhena floribunda hydro ethanol extract

Disease-modifying anti rheumatic drugs

Bovine serum albumin

Phosphate buffered saline

Sprague Dawley rat

Centre for Plant Medicine Research

Ghana Agro Food Company

Acetyl salicylic acid

Histamine receptor 

ANOVA - $\quad$ Analysis of variance
COX - $\quad$ Cyclooxygenase

AUC Area under the curve

\section{Declarations}

\section{Ethics and consent to participate}

This study was approved by the Ethics Committee of Centre for Plant Medicine Research, MampongAkuapem, Ghana. Approval number: CPMR/M.6-PT3/2018.

\section{Consent to publish}

Not applicable

\section{Availability of data and materials}

The datasets used and/or analysed during the current study are available from the corresponding author on reasonable request.

Competing interest

None.

\section{Funding}

Not applicable

\section{Authors' contributions}

SA designed and carried out laboratory work for this study, provided resources for the study, analysed the data and drafted the report. DOM provided resources for the study, analysed the data, reviewed the draft report and prepared the final manuscript. DDO conceptualized the study, provided resources, supervised the work and reviewed the draft report. NO, AOA, AO and LKNO reviewed and edited the final manuscript. 
HOA contributed to drafting and preparation of the final manuscript. All authors have read and approved the manuscript.

\section{$\underline{\text { Acknowledgements }}$}

The authors acknowledge the support and collaboration of scientists and technicians at the Centre for Plant Medicine Research, Mampong-Akuapem, Ghana. We also acknowledge insight into the clinical situation of COVID-19 in Ghana from Dr E. Oduro-Mensah, Medical Superintendent, Ga-East Municipal Hospital, Accra, Ghana.

\section{References}

Abe, H., Katada, K., Orita, M., \& Nishikibe, M. (1991). Effects of calcium antagonists on the erythrocyte membrane. The Journal of Pharmacy and Pharmacology, 43(1), 22-26. https://doi.org/10.1111/j.20427158.1991.tb05441.x

Atanasov, A. G., Waltenberger, B., Pferschy-Wenzig, E.-M., Linder, T., Wawrosch, C., Uhrin, P., Temml, V., Wang, L., Schwaiger, S., Heiss, E. H., Rollinger, J. M., Schuster, D., Breuss, J. M., Bochkov, V., Mihovilovic, M. D., Kopp, B., Bauer, R., Dirsch, V. M., \& Stuppner, H. (2015). Discovery and resupply of pharmacologically active plant-derived natural products: A review. Biotechnology Advances, 33(8), 1582-1614. https://doi.org/https://doi.org/10.1016/j.biotechadv.2015.08.001

Aydin, S., \& Aydin, S. (2020). Could Antihistamines Help in the Treatment and Spread of COVID-19 Via ReModulating Cytokines and by Reducing Sneezing?

Barnes, P. J. (1991). Histamine receptors in the lung. Agents and Actions, 33, 103-122. https://doi.org/10.1007/978-3-0348-7309-3_9

Becker, S., Pflugbeil, C., Gröger, M., Canis, M., Ledderose, G. J., \& Kramer, M. F. (2012). Olfactory dysfunction in seasonal and perennial allergic rhinitis. Acta Oto-Laryngologica, 132(7), 763-768. https://doi.org/10.3109/00016489.2012.656764

Branco, A. C. C. C., Yoshikawa, F. S. Y., Pietrobon, A. J., \& Sato, M. N. (2018). Role of Histamine in Modulating the Immune Response and Inflammation. Mediators of Inflammation, 2018, 1-10. https://doi.org/10.1155/2018/9524075

Brown, A. (2009). Current management of anaphylaxis. Emergencias, 21, 213-223.

Bryce, P. J., Falahati, R., Kenney, L. L., Leung, J., Bebbington, C., Tomasevic, N., Krier, R. A., Hsu, C. L., Shultz, L. D., Greiner, D. L., \& Brehm, M. A. (2016). Humanized mouse model of mast cell-mediated passive cutaneous anaphylaxis and passive systemic anaphylaxis. Journal of Allergy and Clinical Immunology, 138(3), 769-779. https://doi.org/10.1016/j.jaci.2016.01.049 
Burkhardt, A. M., \& Zlotnik, A. (2013). Translating translational research: mouse models of human disease. Cellular \& Molecular Immunology, 10(5), 373-374. https://doi.org/10.1038/cmi.2013.19

Chatterjea, D., Wetzel, A., Mack, M., Engblom, C., Allen, J., Mora, C., Paredes, L., Balsells Hernández, E., \& Martinov, T. (2012). Mast cell degranulation mediates compound 48/80-induced hyperalgesia in mice. Biochemical and Biophysical Research Communications, 425, 237-243.

https://doi.org/10.1016/j.bbrc.2012.07.074

Chopra, Y. M., \& Dandiya, P. C. (1975). The relative role of brain acetylcholine and histamine in perphenazine catatonia and influence of antidepressants and diphenhydramine alone and in combination. Neuropharmacology, 14(8), 555-560. https://doi.org/https://doi.org/10.1016/00283908(75)90120-3

Chukwurah, B. K. C. (1997). Antimicrobial activity of Holarrhena floribunda stem bark ethanol extract. Fitoterapia, 68(2), 180-181.

Church, M. K., James, G. W. L., \& Miller, P. (1974). The inhibitory effect of insulin on pinnal anaphylaxis in the mouse. BRIT.J.PHARMACOL., 52, 454.

Cowden, J. M., Zhang, M., Dunford, P. J., \& Thurmond, R. L. (2010). The Histamine $\mathrm{H}_{4}$ Receptor Mediates Inflammation and Pruritus in Th2-Dependent Dermal Inflammation. Journal of Investigative Dermatology, 130(4), 1023-1033. https://doi.org/10.1038/jid.2009.358

Cragg, G. M., \& Newman, D. J. (2013). Natural products: A continuing source of novel drug leads. Biochimica et Biophysica Acta - General Subjects, 1830(6), 3670-3695.

https://doi.org/10.1016/j.bbagen.2013.02.008

Crunkhorn, P., \& Meacock, S. C. (1971). Mediators of the inflammation induced in the rat paw by carrageenin. British Journal of Pharmacology, 42(3), 392-402. https://doi.org/10.1111/j.14765381.1971.tb07124.x

de Nard, F., Todoerti, M., Grosso, V., Monti, S., Breda, S., Rossi, S., Montecucco, C., \& Caporali, R. (2015). Risk of hepatitis $B$ virus reactivation in rheumatoid arthritis patients undergoing biologic treatment: Extending perspective from old to newer drugs. World Journal of Hepatology. https://doi.org/10.4254/wjh.v7.i3.344

Earp, J. C., Pyszczynski, N. A., Molano, D. S., \& Jusko, W. J. (2008). Pharmacokinetics of dexamethasone in a rat model of rheumatoid arthritis. Biopharmaceutics \&amp; Drug Disposition, 29(6), 366-372. https://doi.org/10.1002/bdd.626

Ennis, M., Pearce, F. L., \& Weston, P. M. (1980). Some studies on the release of histamine from mast cells stimulated with polylysine. British Journal of Pharmacology, 70, 329. https://doi.org/10.1111/j.14765381.1980.tb07940.x 
Evans, H., Killoran, K. E., \& Mitre, E. (2014). Measuring local anaphylaxis in mice. Journal of Visualized Experiments, 92, e52005. https://doi.org/10.3791/52005

Ferré, S., Guix, T., Prat, G., Jane, F., \& Casas, M. (1990). Is experimental catalepsy properly measured? Pharmacology, Biochemistry and Behavior, 35, 753-757. https://doi.org/10.1016/0091-3057(90)90354-K

Franco, N. H., Correia-Neves, M., \& Olsson, I. A. S. (2012). How "humane" is your endpoint? Refining the science-driven approach for termination of animal studies of chronic infection. PLoS Pathogens, 8(1), e1002399. https://doi.org/10.1371/journal.ppat.1002399

Freedberg, D. E., Conigliaro, J., Wang, T. C., Tracey, K. J., Callahan, M. V, Abrams, J. A., Sobieszczyk, M. E., Markowitz, D. D., Gupta, A., O’Donnell, M. R., Li, J., Tuveson, D. A., Jin, Z., Turner, W. C., \& Landry, D. W. (2020). Famotidine Use is Associated with Improved Clinical Outcomes in Hospitalized COVID-19 Patients: A Propensity Score Matched Retrospective Cohort Study. Gastroenterology. https://doi.org/https://doi.org/10.1053/j.gastro.2020.05.053

Gan, T. J. (2010). Diclofenac: an update on its mechanism of action and safety profile. Current Medical Research and Opinion, 26(7), 1715-1731. https://doi.org/10.1185/03007995.2010.486301

Geurdes, H. (2020). Hypothesis Why Vertical SARS-CoV-2 Infection Can Occur and Is Rare. SSRN Electronic Journal. https://doi.org/10.2139/ssrn.3636903

Girija, A. S. S., Shankar, E. M., \& Larsson, M. (2020). Could SARS-CoV-2-Induced Hyperinflammation Magnify the Severity of Coronavirus Disease (CoViD-19) Leading to Acute Respiratory Distress Syndrome? Frontiers in Immunology, 11, 1206. https://doi.org/10.3389/fimmu.2020.01206

Gnangoran, B., N'Guessan, B., Amoateng, P., Dosso, K., Yapo, A., \& Ehile, E. E. (2012). Hypoglycaemic activity of ethanolic leaf extract and fractions of Holarrhena floribunda (Apocynaceae). Journal of Medical and Biomedical Sciences, 1, 46-54.

Gupta, M., Mazumder, U. K., Gomathi, P., \& Selvan, V. T. (2006). Antiinflammatory evaluation of leaves of Plumeria acuminata. BMC Complementary and Alternative Medicine, 6(1), 36.

https://doi.org/10.1186/1472-6882-6-36

Hill, S. J. (1992). Multiple histamine receptors: properties and functional characteristics. Biochemical Society Transactions, 20(1), 122-125. https://doi.org/10.1042/bst0200122

Hirasawa, N, Murakami, A., \& Ohuchi, K. (2001). Expression of 74-kDa histidine decarboxylase protein in a macrophage-like cell line RAW 264.7 and inhibition by dexamethasone. European Journal of Pharmacology, 418(1-2), 23-28. https://doi.org/10.1016/s0014-2999(01)00931-1

Hirasawa, Noriyasu. (2019). Expression of Histidine Decarboxylase and Its Roles in Inflammation. International Journal of Molecular Sciences, 20(2), 376. https://doi.org/10.3390/ijms20020376 
Huang, C., Wang, Y., Li, X., Ren, L., Zhao, J., Hu, Y., Zhang, L., Fan, G., Xu, J., Gu, X., Cheng, Z., Yu, T., Xia, J., Wei, Y., Wu, W., Xie, X., Yin, W., Li, H., Liu, M., ... Cao, B. (2020). Clinical features of patients infected with 2019 novel coronavirus in Wuhan, China. The Lancet, 395(10223), 497-506.

https://doi.org/10.1016/S0140-6736(20)30183-5

Hwang, S. B., Lam, M. H., Li, C. L., \& Shen, T. Y. (1996). Release of platelet activating factor and its involvement in the first phase of carrageenin-induced rat foot edema. European Journal of Pharmacology, 33(5), 693-701. https://doi.org/10.1016/0014-2999(86)90636-9

Jadhav, J. H., Balsara, J. J., \& Chandorkar, A. G. (1983). Involvement of histaminergic mechanisms in the cataleptogenic effect of clonidine in mice. Journal of Pharmacy and Pharmacology, 35(10), 671-673. https://doi.org/10.1111/j.2042-7158.1983.tb02864.x

Jemima, E. A., Prema, A., \& Thangam, E. B. (2014). Functional characterization of histamine H4 receptor on human mast cells. Molecular Immunology, 62(1), 19-28.

https://doi.org/10.1016/j.molimm.2014.05.007

Juskewitch, J. E., Knudsen, B. E., Platt, J. L., Nath, K. A., Knutson, K. L., Brunn, G. J., \& Grande, J. P. (2012). LPS-induced murine systemic inflammation is driven by parenchymal cell activation and exclusively predicted by early MCP-1 plasma levels. American Journal of Pathology, 180(1), 32-40. https://doi.org/10.1016/j.ajpath.2011.10.001

Kaibara, N., Hotokebuchi, T., Takagishi, K., \& Katsuki, I. (1983). Paradoxical effects of cyclosporin A on collagen arthritis in rats. Journal of Experimental Medicine, 158(6), 2007-2015.

https://doi.org/10.1084/jem.158.6.2007

Kelmenson, A. T., Rao, N. K., \& Raizman, M. B. (2013). 17 - Treatment of Allergic Eye Disease (E. J. Holland, M. J. Mannis, \& W. B. B. T.-O. S. D. C. Lee Conjunctiva and Tear Film (eds.); pp. 117-124). W.B. Saunders. https://doi.org/https://doi.org/10.1016/B978-1-4557-2876-3.00017-1

Kilinc, E., Baranoğlu, Y., \& Baranoğlu Kilinç, Y. (2020). Mast cell stabilizers as a supportive therapy can contribute to alleviate fatal inflammatory responses and severity of pulmonary complications in COVID19 infection. Anadolu Kliniği Tıp Bilimleri Dergisi, 25, 111-118.

https://doi.org/10.21673/anadoluklin.720116

Kim, S. H., Choi, C. H., Kim, S. Y., Eun, J. S., \& Shin, T. Y. (2005). Anti-allergic effects of Artemisia iwayomogi on mast cell-mediated allergy model. Experimental Biology and Medicine, 230, 82-88. https://doi.org/10.1177/153537020523000111

Kritas, S. K., Ronconi, G., Caraffa, A., Gallenga, C. E., Ross, R., \& Conti, P. (2020). Mast cells contribute to coronavirus-induced inflammation: new anti-inflammatory strategy. In Journal of biological regulators and homeostatic agents (Vol. 34, Issue 1, pp. 9-14). https://doi.org/10.23812/20-Editorial-Kritas 
Laine, L., Smith, R., Min, K., Chen, C., \& Dubois, R. W. (2006). Systematic review: The lower gastrointestinal adverse effects of non-steroidal anti-inflammatory drugs. Alimentary Pharmacology and Therapeutics, 22(5), 751-767. https://doi.org/10.1111/j.1365-2036.2006.03043.x

Lakdawala, A. D., Dadkar, N. K., \& Dohadwalla, A. N. (1980). Action of clonidine on the mast cells of rats. Journal of Pharmacy and Pharmacology, 32(1), 790-791. https://doi.org/10.1111/j.20427158.1980.tb13070.x

Larsson, P., Kleinau, S., Holmdahl, R., \& Klareskog, L. (1990). Homologous type II collagen-induced arthritis in rats. Characterization of the disease and demonstration of clinically distinct forms of arthritis in two strains of rats after immunization with the same collagen preparation. Arthritis and Rheumatism, 33(5), 693-701. https://doi.org/10.1002/art.1780330512

Lasselin, J., Schedlowski, M., Karshikoff, B., Engler, H., Lekander, M., \& Konsman, J. P. (2020). Comparison of bacterial lipopolysaccharide-induced sickness behavior in rodents and humans: Relevance for symptoms of anxiety and depression. Neuroscience and Biobehavioral Reviews, 115(May), 15-24.

Lechien, J. R., Chiesa-Estomba, C. M., Place, S., Van Laethem, Y., Cabaraux, P., Mat, Q., Huet, K., Plzak, J., Horoi, M., Hans, S., Rosaria Barillari, M., Cammaroto, G., Fakhry, N., Martiny, D., Ayad, T., Jouffe, L., Hopkins, C., Saussez, S., \& YO-IFOS, C.-19 T. F. of. (2020). Clinical and epidemiological characteristics of 1420 European patients with mild-to-moderate coronavirus disease 2019. Journal of Internal Medicine, n/a(n/a). https://doi.org/10.1111/joim.13089

Lee, J.-K., Lee, S., Baek, M.-C., Lee, B.-H., Lee, H.-S., Kwon, T. K., Park, P.-H., Shin, T.-Y., Khang, D., \& Kim, S.-H. (2017). Association between perfluorooctanoic acid exposure and degranulation of mast cells in allergic inflammation. Journal of Applied Toxicology, 37(5), 554-562. https://doi.org/10.1002/jat.3389

Lieberman, P., Nicklas, R. A., Oppenheimer, J., Kemp, S. F., Lang, D. M., Bernstein, D. I., Bernstein, J. A., Burks, A. W., Feldweg, A. M., Fink, J. N., Greenberger, P. A., Golden, D. B. K., James, J. M., Kemp, S. F., Ledford, D. K., Lieberman, P., Sheffer, A. L., Bernstein, D. I., Blessing-Moore, J., ... Wallace, D. (2010). The diagnosis and management of anaphylaxis practice parameter: 2010 Update. Journal of Allergy and Clinical Immunology, 126(3), 477-480.e42. https://doi.org/https://doi.org/10.1016/j.jaci.2010.06.022

Liu, J., Cao, R., Xu, M., Wang, X., Zhang, H., Hu, H., Li, Y., Hu, Z., Zhong, W., \& Wang, M. (2020). Hydroxychloroquine, a less toxic derivative of chloroquine, is effective in inhibiting SARS-CoV-2 infection in vitro. Cell Discovery, 6, 16. https://doi.org/10.1038/s41421-020-0156-0

Lo, T. N., Saul, W. F., \& Lau, S. S. (1987). Carrageenan-stimulated release of arachidonic acid and of lactate dehydrogenase from rat pleural cells. Biochemical Pharmacology, 36(14), 2405-2413. https://doi.org/https://doi.org/10.1016/0006-2952(87)90610-1

Lowry, S. F. (2005). Human endotoxemia: A model for mechanistic insight and therapeutic targeting. Shock, 24, 94-100. https://doi.org/10.1097/01.shk.0000191340.23907.a1 
Malone, R., Tisdall, P., Fremont-Smith, P., Liu, Y., Huang, X.-P., White, K., Miorin, L., Moreno, E., Alon, A., Delaforge, E., Hennecker, C., Wang, G., Pottel, J., Bona, R., Smith, N., Hall, J., Shapiro, G., Clark, H., Mittermaier, A., \& Ricke, D. (2020). COVID-19: Famotidine, Histamine, Mast Cells, and Mechanisms. In Research square. https://doi.org/10.21203/rs.3.rs-30934/v2

Minozzi, S., Bonovas, S., Lytras, T., Pecoraro, V., González-Lorenzo, M., Bastiampillai, A. J., Gabrielli, E. M., Lonati, A. C., Moja, L., Cinquini, M., Marino, V., Matucci, A., Milano, G. M., Tocci, G., Scarpa, R., Goletti, D., \& Cantini, F. (2016). Risk of infections using anti-TNF agents in rheumatoid arthritis, psoriatic arthritis, and ankylosing spondylitis: A systematic review and meta-analysis. In Expert Opinion on Drug Safety (Vol. 15, pp. 11-34). https://doi.org/10.1080/14740338.2016.1240783

Morris, C. (2003). Carrageenan-Induced Paw Edema in the Rat and Mouse. Methods in Molecular Biology, Vol. 225; Inflammation Protocols, 225, 115-121. https://doi.org/10.1385/1-59259-374-7:115

Nantel, F., Denis, D., Gordon, R., Northey, A., Cirino, M., Metters, K. M., \& Chan, C. C. (1999). Distribution and regulation of cyclooxygenase-2 in carrageenan-induced inflammation. British Journal of Pharmacology, 128(4), 853-859. https://doi.org/10.1038/sj.bjp.0702866

Ohsawa, Y., \& Hirasawa, N. (2014). The role of histamine H1 and H4 receptors in atopic dermatitis: from basic research to clinical study. Allergology International: Official Journal of the Japanese Society of Allergology, 63(4), 533-542. https://doi.org/10.2332/allergolint.13-RA-0675

Ornstein, M. H., \& Sperber, K. (1996). The antiinflammatory and antiviral effects of hydroxychloroquine in two patients with acquired immunodeficiency syndrome and active inflammatory arthritis. Arthritis and Rheumatism, 39(1), 157-161. https://doi.org/10.1002/art.1780390122

Pahwa, R., \& Jialal, I. (2019). Chronic Inflammation - StatPearls - NCBI Bookshelf. In Stat Pearls.

Pan, S. Y., Zhou, S. F., Gao, S. H., Yu, Z. L., Zhang, S. F., Tang, M. K., Sun, J. N., Ma, D. L., Han, Y. F., Fong, W. F., \& Ko, K. M. (2013). New perspectives on how to discover drugs from herbal medicines: CAM'S outstanding contribution to modern therapeutics. Evidence-Based Complementary and Alternative Medicine, 2013, 1-25. https://doi.org/10.1155/2013/627375

Pearce, F. L. (1985). Calcium and mast cell activation. British Journal of Clinical Pharmacology, 20 Suppl 2(Suppl 2), 267S-274S. https://doi.org/10.1111/j.1365-2125.1985.tb02812.x

Perez, E. M., Rogers, L. K., Smith, C. V, \& Weisman, L. E. (1998). Pharmacokinetics of Dexamethasone in Rats 346. Pediatric Research, 43(4), 61. https://doi.org/10.1203/00006450-199804001-00367

Posadas, I., Bucci, M., Roviezzo, F., Rossi, A., Parente, L., Sautebin, L., \& Cirino, G. (2004). Carrageenaninduced mouse paw oedema is biphasic, age-weight dependent and displays differential nitric oxide cyclooxygenase-2 expression. British Journal of Pharmacology, 142, 331-338.

https://doi.org/10.1038/sj.bjp.0705650 
Qiao, H., Andrade, M. V, Lisboa, F. A., Morgan, K., \& Beaven, M. A. (2006). FceR1 and toll-like receptors mediate synergistic signals to markedly augment production of inflammatory cytokines in murine mast cells. Blood, 107(2), 610-618. https://doi.org/10.1182/blood-2005-06-2271

Ray, M. A., Johnston, N. A., Verhulst, S., Trammell, R. A., \& Toth, L. A. (2010). Identification of markers for imminent death in mice used in longevity and aging research. Journal of the American Association for Laboratory Animal Science, 49(3), 282-288.

Reimann, T., Büscher, D., Hipskind, R. A., Krautwald, S., Lohmann-Matthes, M. L., \& Baccarini, M. (1994). Lipopolysaccharide induces activation of the Raf-1/MAP kinase pathway. A putative role for Raf-1 in the induction of the IL-1 beta and the TNF-alpha genes. Journal of Immunology (Baltimore, Md. : 1950), 153(12), 5740-5749.

Roth, G. A., Abate, D., Abate, K. H., Abay, S. M., Abbafati, C., Abbasi, N., Abbastabar, H., Abd-Allah, F., Abdela, J., Abdelalim, A., Abdollahpour, I., Abdulkader, R. S., Abebe, H. T., Abebe, M., Abebe, Z., Abejie, A. N., Abera, S. F., Abil, O. Z., Abraha, H. N., ... Murray, C. J. L. (2018). Global, regional, and national age-sexspecific mortality for 282 causes of death in 195 countries and territories, 1980-2017: a systematic analysis for the Global Burden of Disease Study 2017. The Lancet, 392(10159), 1736-1788. https://doi.org/10.1016/S0140-6736(18)32203-7

Ruan, Q., Yang, K., Wang, W., Jiang, L., \& Song, J. (2020). Clinical predictors of mortality due to COVID-19 based on an analysis of data of 150 patients from Wuhan, China. Intensive Care Medicine, 46(5), 846848. https://doi.org/10.1007/s00134-020-05991-x

Salvemini, D., Wang, Z. Q., Wyatt, P. S., Bourdon, D. M., Marino, M. H., Manning, P. T., \& Currie, M. G. (1996). Nitric oxide: A key mediator in the early and late phase of carrageenan-induced rat paw inflammation. British Journal of Pharmacology, 118(4), 829-838. https://doi.org/10.1111/j.1476-5381.1996.tb15475.x

Sanberg, P. R. (1980). Haloperidol-induced catalepsy is mediated by postsynaptic dopamine receptors. Nature, 284(5755), 472-473. https://doi.org/10.1038/284472a0

Savard, C., Lema, P. P., Hélie, P., \& Vachon, P. (2009). Effects of timing of dexamethasone treatment on the outcome of collagenase-induced intracerebral hematoma in rats. Comparative Medicine, 59(5), 444-448.

Schemann, M., Kugler, E. M., Buhner, S., Eastwood, C., Donovan, J., Jiang, W., \& Grundy, D. (2012). The Mast Cell Degranulator Compound 48/80 Directly Activates Neurons. PLoS ONE, 7(12), e52104. https://doi.org/10.1371/journal.pone.0052104

Scholer, D. W., Ku, E. C., Boettcher, I., \& Schweizer, A. (1986). Pharmacology of diclofenac sodium. The American Journal of Medicine, 80(4B), 34-38. https://doi.org/10.1016/0002-9343(86)90077-x

Seok, J., Warren, H. S., Cuenca, A. G., Mindrinos, M. N., Baker, H. V, Xu, W., Richards, D. R., McDonald-Smith, G. P., Gao, H., Hennessy, L., Finnerty, C. C., López, C. M., Honari, S., Moore, E. E., Minei, J. P., Cuschieri, J., 
Bankey, P. E., Johnson, J. L., Sperry, J., ... Tompkins, R. G. (2013). Genomic responses in mouse models poorly mimic human inflammatory diseases. Proceedings of the National Academy of Sciences of the United States of America, 110(9), 3507-3512. https://doi.org/10.1073/pnas.1222878110

Shapira, L., Soskolne, W. A., Houri, Y., Barak, V., Halabi, A., \& Stabholz, A. (1996). Protection against endotoxic shock and lipopolysaccharide-induced local inflammation by tetracycline: correlation with inhibition of cytokine secretion. Infection and Immunity, 64(3), 825-828.

https://doi.org/10.1128/IAl.64.3.825-828.1996

Shinde, U. A., Phadke, A. S., Nair, A. M., Mungantiwar, A. A., Dikshit, V. J., \& Saraf, M. N. (1999). Membrane stabilizing activity - a possible mechanism of action for the anti-inflammatory activity of Cedrus deodara wood oil. Fitoterapia, 70(3), 251-257. https://doi.org/https://doi.org/10.1016/S0367326X(99)00030-1

Singh, R. K., \& Pandey, B. L. (1996). Anti-inflammatory activity of seed extracts of Pongamia pinnata in rat. Indian Journal of Physiology and Pharmacology, 40, 355-358.

Song, P., Li, W., Xie, J., Hou, Y., \& You, C. (2020). Cytokine storm induced by SARS-CoV-2. Clinica Chimica Acta; International Journal of Clinical Chemistry, 509, 280-287.

https://doi.org/10.1016/j.cca.2020.06.017

Stanworth, D. R. (1973). Immediate hypersensitivity: the molecular basis of the allergic response (Issue 28). North-Holland Publishing Company.

Strait, R. T., Morris, S. C., Yang, M., Qu, X. W., \& Finkelman, F. D. (2002). Pathways of anaphylaxis in the mouse. Journal of Allergy and Clinical Immunology, 109(4), 658-668.

https://doi.org/10.1067/mai.2002.123302

Straub, R. H., \& Schradin, C. (2016). Chronic inflammatory systemic diseases - an evolutionary trade-off between acutely beneficial but chronically harmful programs. Evolution, Medicine, and Public Health, 3751. https://doi.org/10.1093/emph/eow001

Tasaka, K., Mio, M., \& Okamoto, M. (1986). Intracellular calcium release induced by histamine releasers and its inhibition by some antiallergic drugs. Annals of Allergy, 56, 464-469.

Thangam, E. B., Jemima, E. A., Singh, H., Baig, M. S., Khan, M., Mathias, C. B., Church, M. K., \& Saluja, R. (2018). The Role of Histamine and Histamine Receptors in Mast Cell-Mediated Allergy and Inflammation: The Hunt for New Therapeutic Targets. Frontiers in Immunology, 9, 1873.

https://doi.org/10.3389/fimmu.2018.01873

Thomford, N. E., Senthebane, D. A., Rowe, A., Munro, D., Seele, P., Maroyi, A., \& Dzobo, K. (2018). Natural Products for Drug Discovery in the 21st Century: Innovations for Novel Drug Discovery. International Journal of Molecular Sciences, 19(6), 1-29. https://doi.org/10.3390/ijms19061578 
Ullman-Culleré, M. H., \& Foltz, C. J. (1999). Body condition scoring: a rapid and accurate method for assessing health status in mice. Laboratory Animal Science, 49(3), 319-323.

Vinegar, R., Schreiber, W., \& Hugo, R. (1969). Biphasic development of carrageenin edema in rats. Journal of Pharmacology and Experimental Therapeutics, 166(1), 96 LP - 103.

http://jpet.aspetjournals.org/content/166/1/96.abstract

Voilley, N., de Weille, J., Mamet, J., \& Lazdunski, M. (2001). Nonsteroid anti-inflammatory drugs inhibit both the activity and the inflammation-induced expression of acid-sensing ion channels in nociceptors. The Journal of Neuroscience: The Official Journal of the Society for Neuroscience, 21(20), 8026-8033. https://doi.org/10.1523/JNEUROSCI.21-20-08026.2001

Waalkes, T. P., \& Coburn, H. (1960). The role of histamine and serotonin during anaphylaxis in the mouse. Journal of Allergy, 31(2), 151-161. https://doi.org/10.1016/0021-8707(60)90038-1

White, M. V. (1990). The role of histamine in allergic diseases. The Journal of Allergy and Clinical Immunology, 86(4(2)), 599-605. https://doi.org/10.1016/S0091-6749(05)80223-4

Winbery, S. L., \& Lieberman, P. L. (2002). Histamine and antihistamines in anaphylaxis. Clinical Allergy and Immunology, 17, 287-317.

Winter, C. A., Risley, E. A., \& Nuss, G. W. (1962). Carrageenin-Induced Edema in Hind Paw of the Rat as an Assay for Antiinflammatory Drugs. Proceedings of the Society for Experimental Biology and Medicine, 111, 544-547. https://doi.org/10.3181/00379727-111-27849

Yang, C., Mo, X., Lv, J., Liu, X., Yuan, M., Dong, M., Li, L., Luo, X., Fan, X., Jin, Z., Liu, Z., \& Liu, J. (2012). Lipopolysaccharide enhances $\mathrm{Fc} \otimes \mathrm{RI}$-mediated mast cell degranulation by increasing $\mathrm{Ca} 2+$ entry through store-operated $\mathrm{Ca} 2+$ channels: implications for lipopolysaccharide exacerbating allergic asthma. Experimental Physiology, 97(12), 1315-1327. https://doi.org/10.1113/expphysiol.2012.065854

Ye, Q., Wang, B., \& Mao, J. (2020). The pathogenesis and treatment of the 'Cytokine Storm" in COVID-19.' Journal of Infection, 80(6), 607-613. https://doi.org/10.1016/j.jinf.2020.03.037

Zatroch, K. K., Knight, C. G., Reimer, J. N., \& Pang, D. S. J. (2017). Refinement of intraperitoneal injection of sodium pentobarbital for euthanasia in laboratory rats (Rattus norvegicus). BMC Veterinary Research, 13(1), 60. https://doi.org/10.1186/s12917-017-0982-y

Zhang, C., Wu, Z., Li, J.-W., Zhao, H., \& Wang, G.-Q. (2020). Cytokine release syndrome in severe COVID-19: interleukin-6 receptor antagonist tocilizumab may be the key to reduce mortality. International Journal of Antimicrobial Agents, 55(5), 105954. https://doi.org/10.1016/j.ijantimicag.2020.105954

Zwickl, H., Zwickl-Traxler, E., \& Pecherstorfer, M. (2019). Is Neuronal Histamine Signaling Involved in Cancer Cachexia? Implications and Perspectives. Frontiers in Oncology, 9, 1409.

https://doi.org/10.3389/fonc.2019.01409

Page 26/40 
Figures

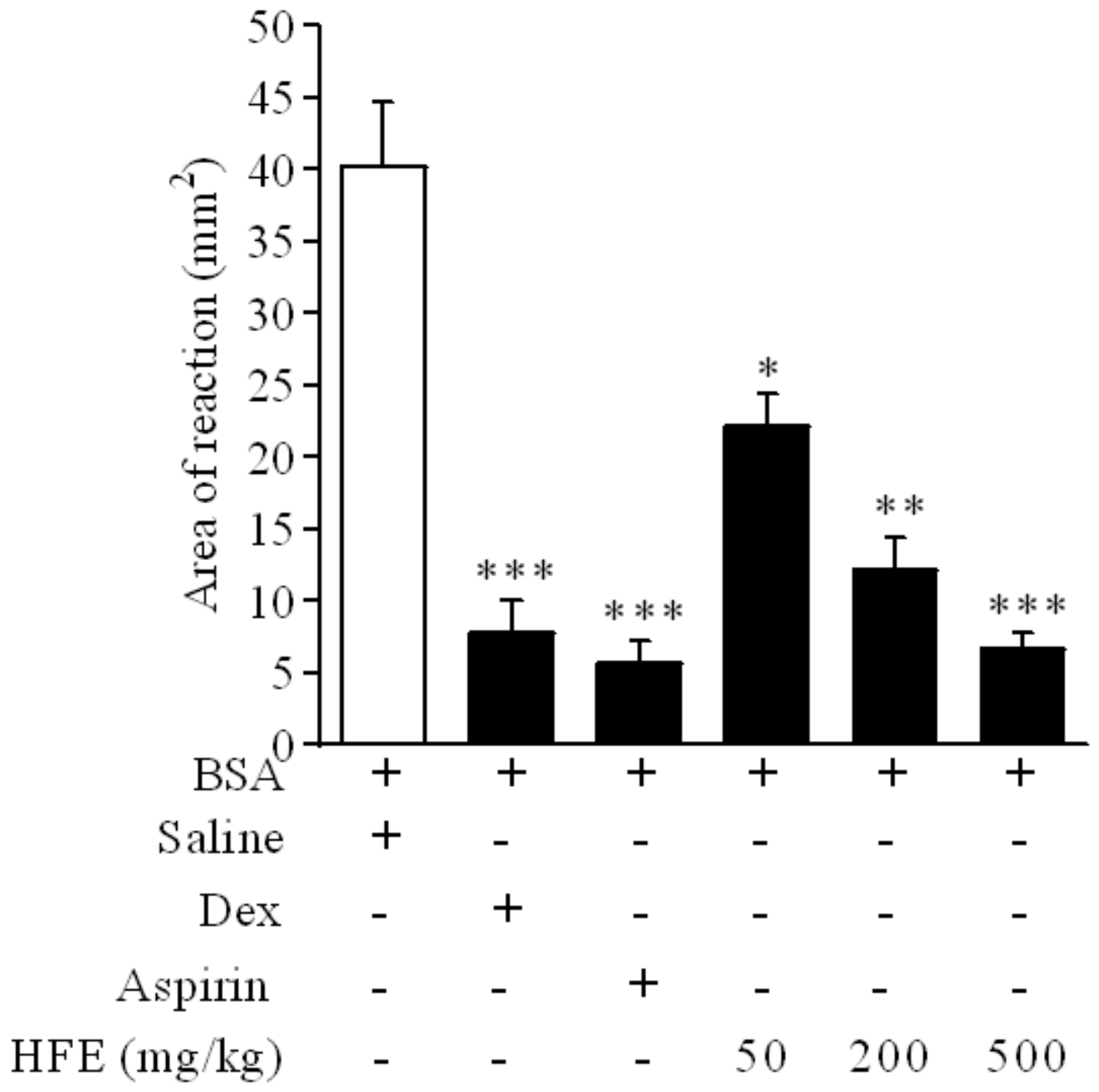

Figure 1

Sensitized mice received normal saline $10 \mathrm{ml} / \mathrm{kg}$, aspirin $100 \mathrm{mg} / \mathrm{kg}$, dexamethasone $0.3 \mathrm{mg} / \mathrm{kg}$ or HFE $50-500 \mathrm{mg} / \mathrm{kg}$, p.o. Data were analysed by one-way ANOVA followed Dunnet's post hoc test, and are presented as mean \pm S.E.M of $n=5$. Significance is relative to saline-treated control. ${ }^{*} P<0.01,{ }^{*} P<$ $0.001, * * * P<0.0001$. 


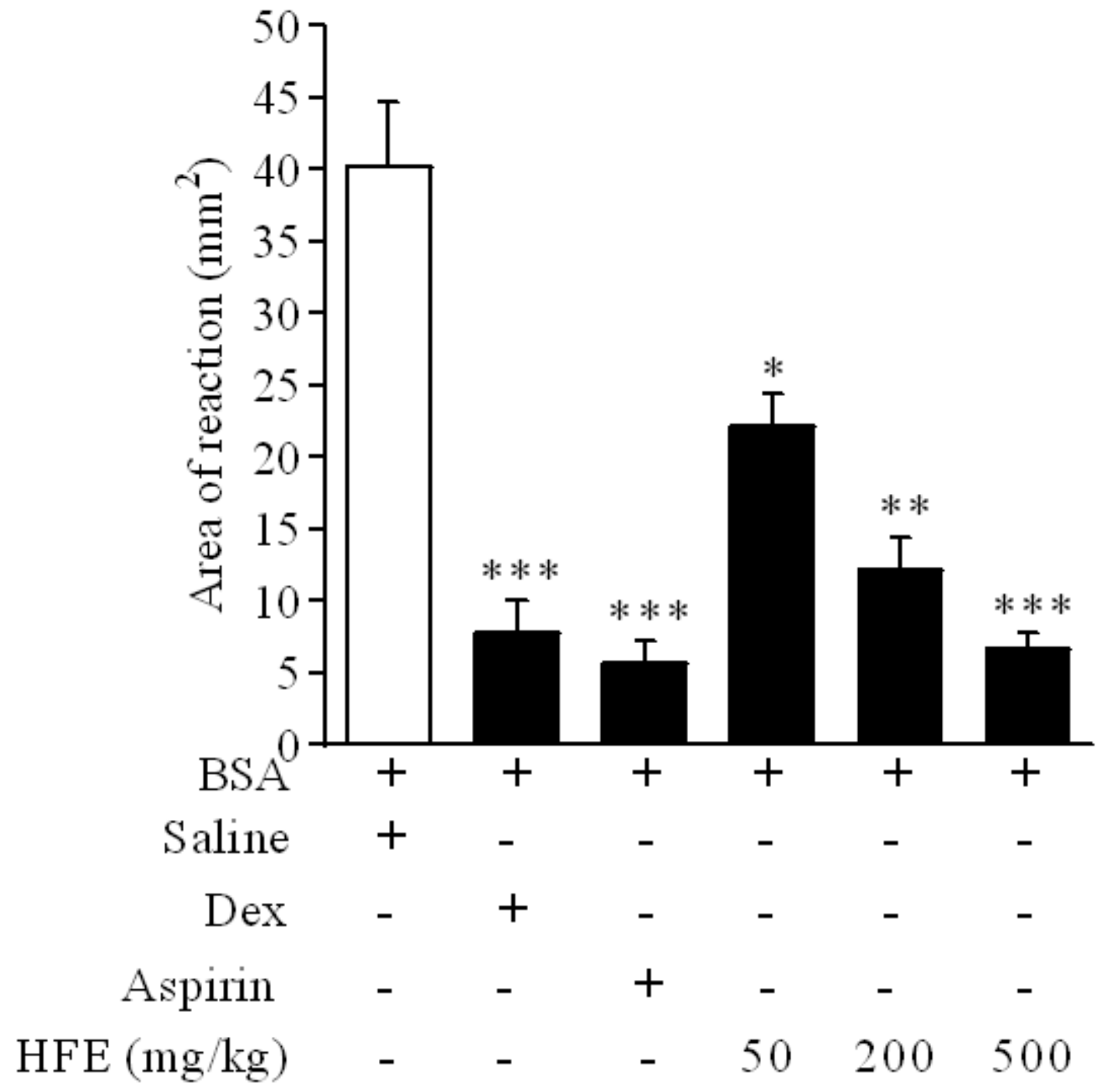

Figure 1

Sensitized mice received normal saline $10 \mathrm{ml} / \mathrm{kg}$, aspirin $100 \mathrm{mg} / \mathrm{kg}$, dexamethasone $0.3 \mathrm{mg} / \mathrm{kg}$ or HFE $50-500 \mathrm{mg} / \mathrm{kg}$, p.o. Data were analysed by one-way ANOVA followed Dunnet's post hoc test, and are presented as mean \pm S.E.M of $n=5$. Significance is relative to saline-treated control. ${ }^{\star} P<0.01,{ }^{\star \star} P<$ $0.001, * \star * P<0.0001$. 


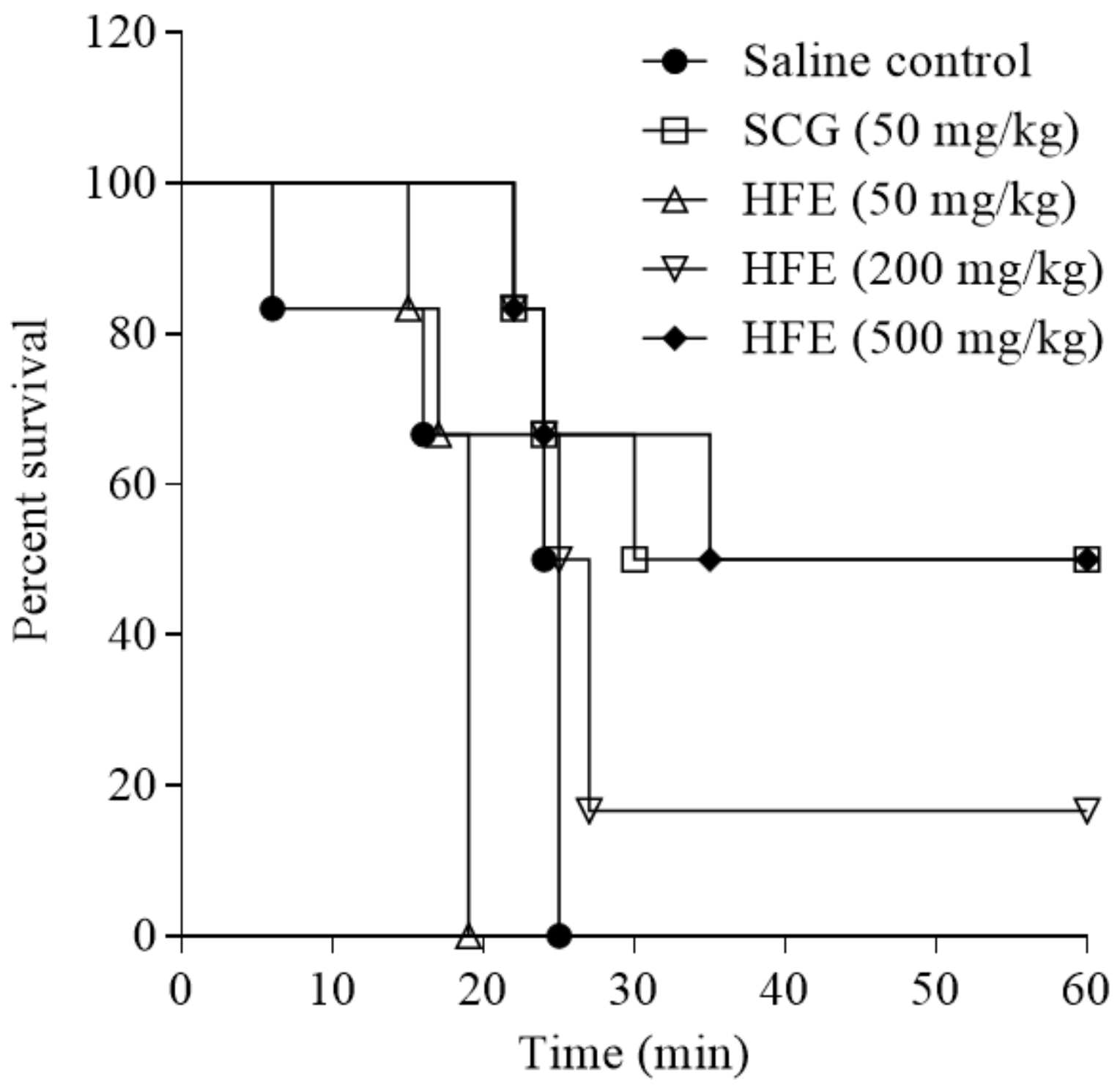

Figure 2

C57BL/ 6 mice received normal saline $10 \mathrm{ml} / \mathrm{kg}$, sodium cromoglycate (SCG) $50 \mathrm{mg} / \mathrm{kg}$ or HFE 50-500 $\mathrm{mg} / \mathrm{kg}$ p.o. $1 \mathrm{~h}$ prior to challenge. Data $(\mathrm{n}=6)$ were analysed by Log-rank (Mantel Cox) test. Differences between the control plot and survival plots for treatment groups were significant $(P \leq 0.001)$ between 20-60 min. 


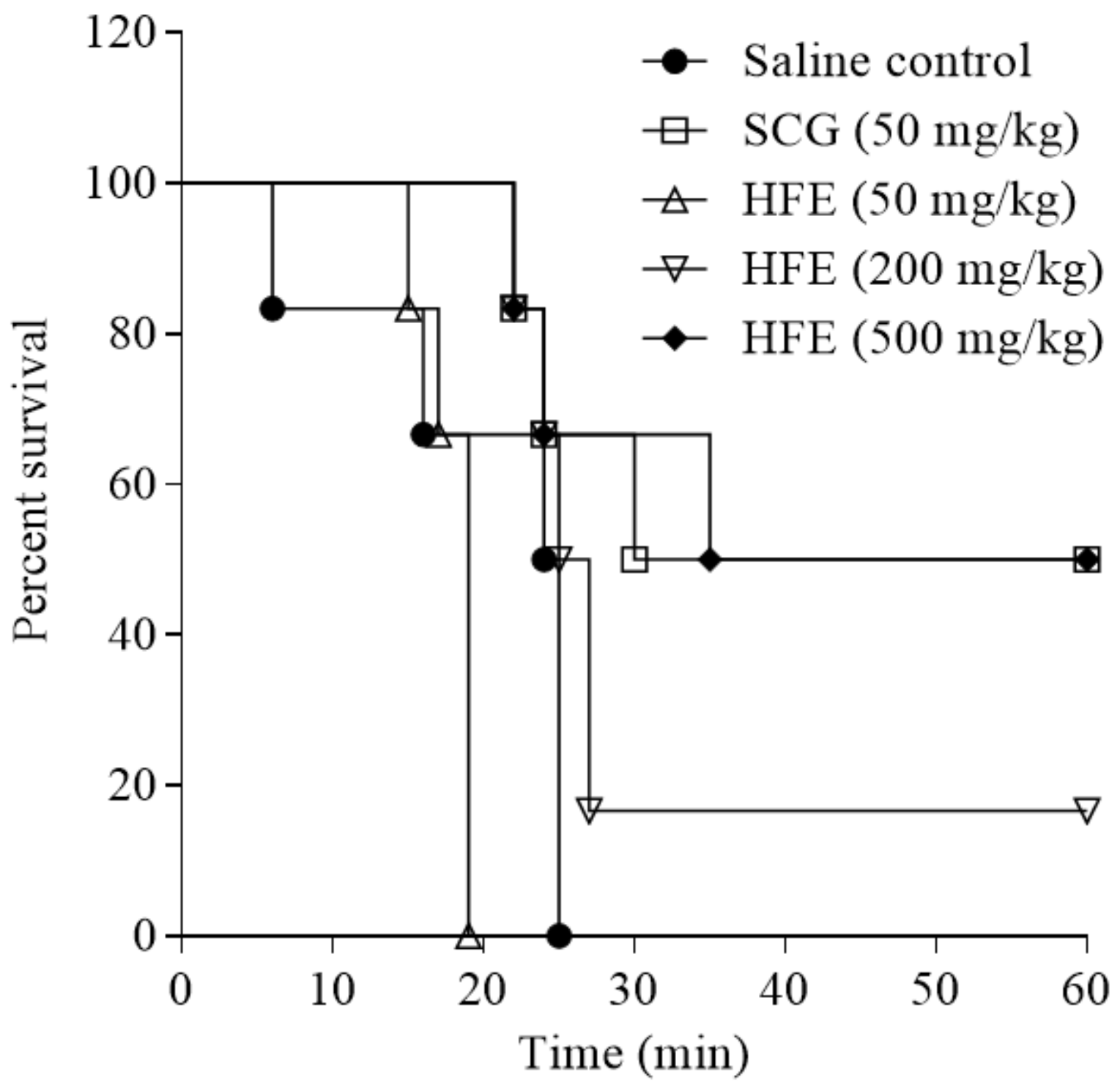

Figure 2

C57BL/ 6 mice received normal saline $10 \mathrm{ml} / \mathrm{kg}$, sodium cromoglycate (SCG) $50 \mathrm{mg} / \mathrm{kg}$ or HFE 50-500 $\mathrm{mg} / \mathrm{kg}$ p.o. $1 \mathrm{~h}$ prior to challenge. Data $(\mathrm{n}=6)$ were analysed by Log-rank (Mantel Cox) test. Differences between the control plot and survival plots for treatment groups were significant $(P \leq 0.001)$ between 20-60 min. 
A

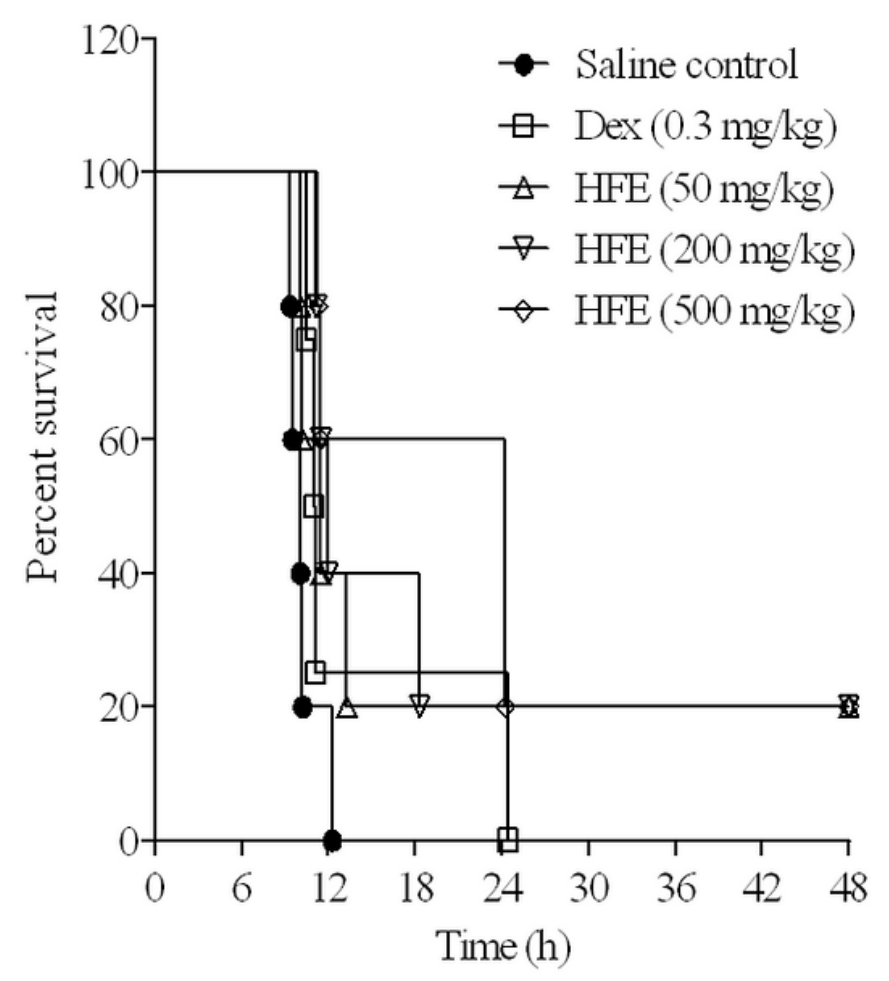

B

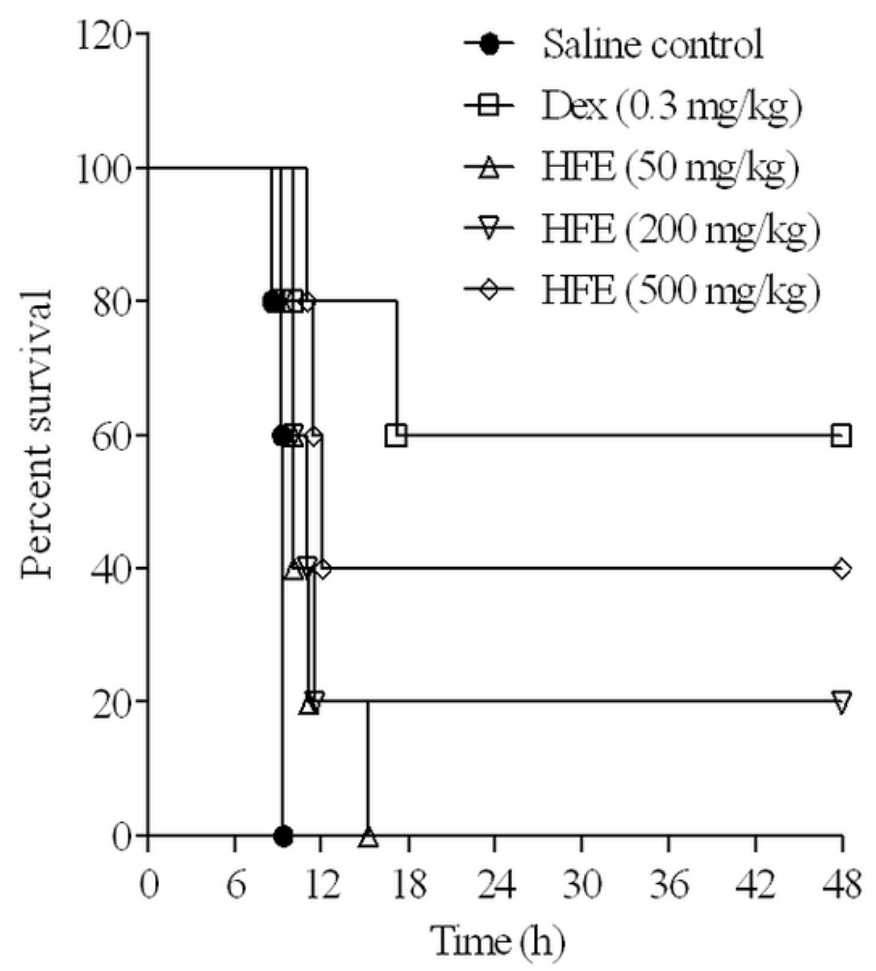

Figure 3

Sprague-Dawley rats received saline $10 \mathrm{ml} / \mathrm{kg}$, dexamethasone $0.3 \mathrm{mg} / \mathrm{kg}$ or HFE $50-500 \mathrm{mg} / \mathrm{kg}$, either prophylactic $(A)$ or therapeutic $(B)$. Data $(n=6)$ were analysed using Log-rank (Mantel Cox) test. Differences in survival curves between the control and HFE treatment groups were significant for prophylactic HFE administration at $500 \mathrm{mg} / \mathrm{kg}(P \leq 0.0198)$ and all therapeutic HFE doses $(P \leq 0.0412-$ 0.0034). 
A

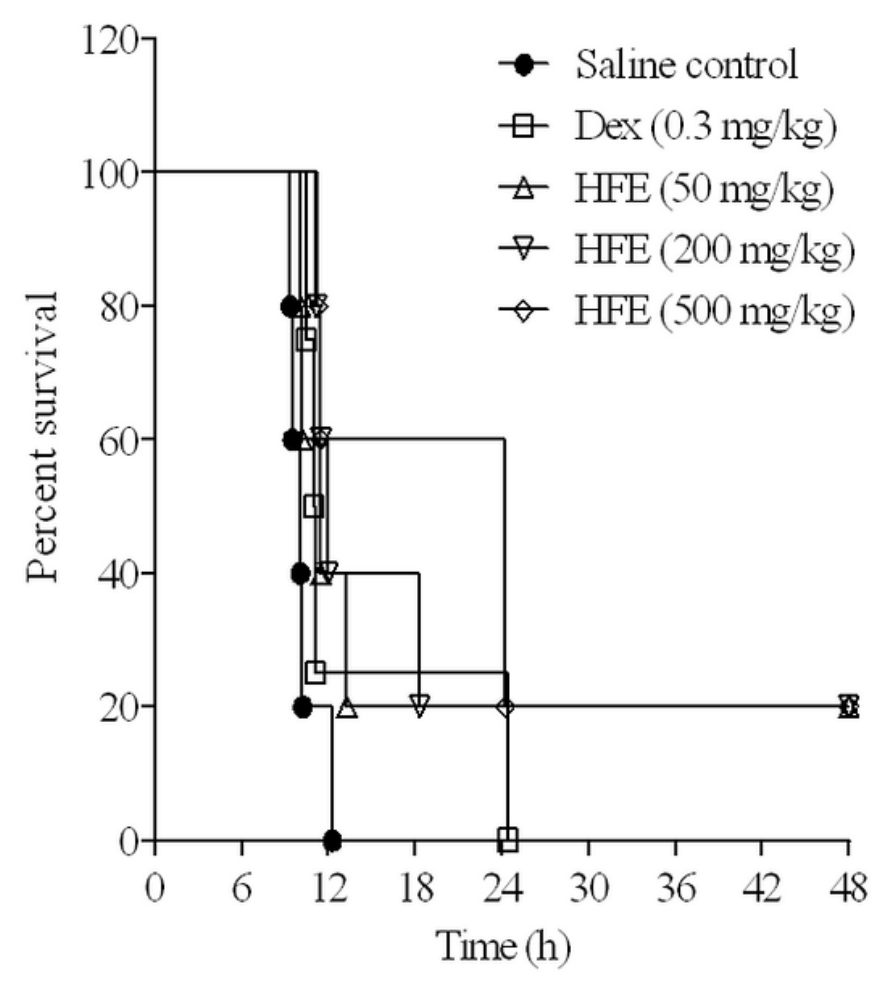

B

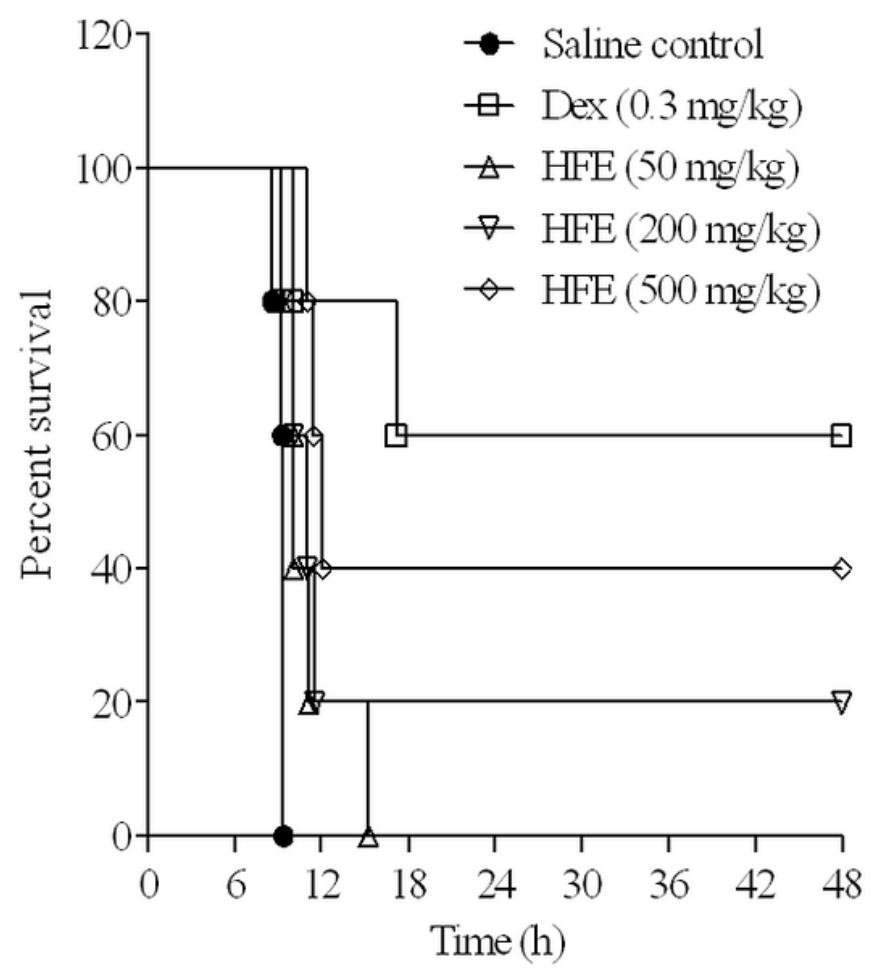

Figure 3

Sprague-Dawley rats received saline $10 \mathrm{ml} / \mathrm{kg}$, dexamethasone $0.3 \mathrm{mg} / \mathrm{kg}$ or HFE $50-500 \mathrm{mg} / \mathrm{kg}$, either prophylactic $(A)$ or therapeutic $(B)$. Data $(n=6)$ were analysed using Log-rank (Mantel Cox) test. Differences in survival curves between the control and HFE treatment groups were significant for prophylactic HFE administration at $500 \mathrm{mg} / \mathrm{kg}(P \leq 0.0198)$ and all therapeutic HFE doses $(P \leq 0.0412-$ 0.0034). 


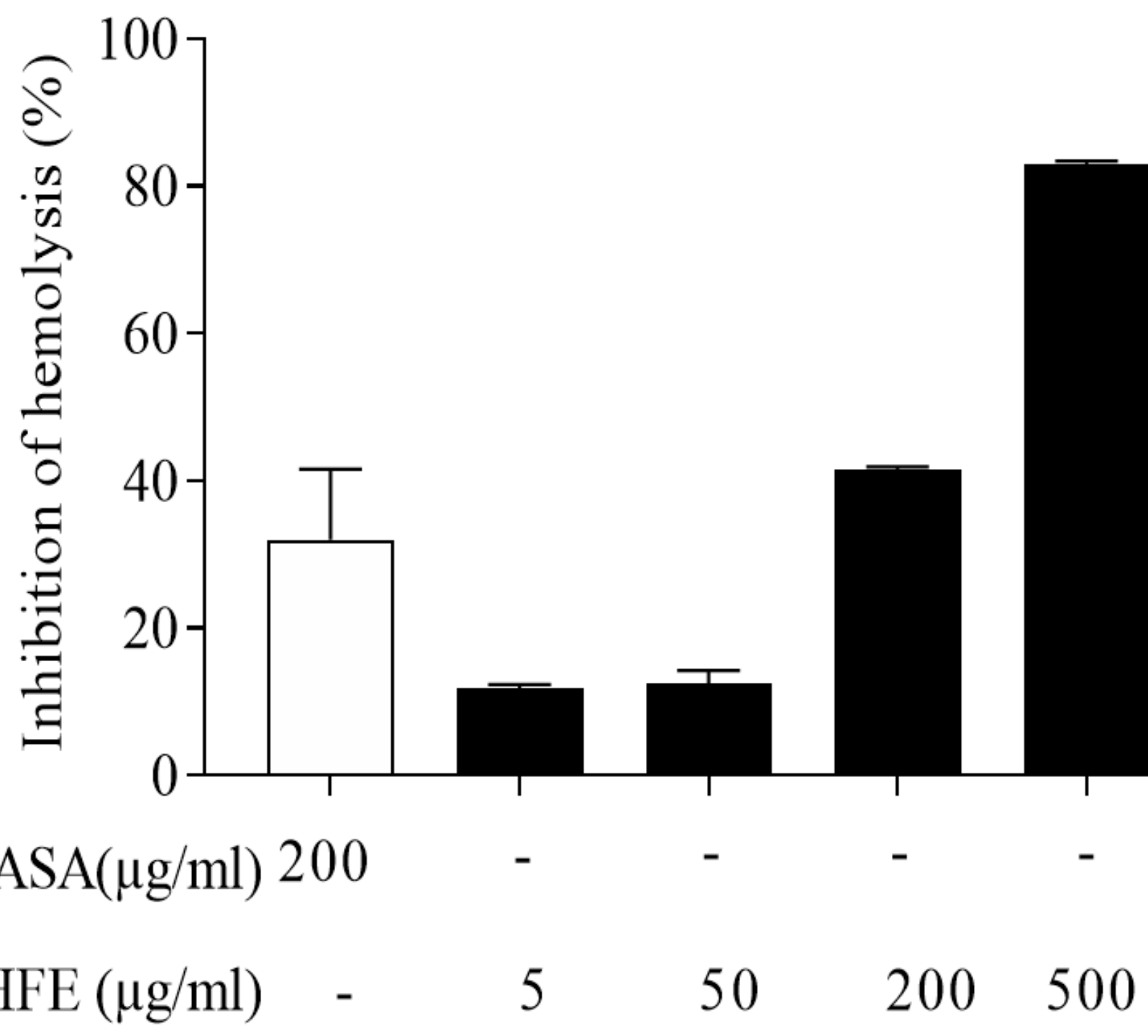

Figure 4

Whole blood was collected from rats under anaesthesia, washed and reconstituted as a $40 \% \mathrm{v} / \mathrm{v}$ red blood cell suspension. Red blood cell suspensions were incubated with $\operatorname{HFE}(5,50,200$ or $500 \mu \mathrm{g} / \mathrm{ml})$. Acetyl salicylic acid (ASA) $200 \mu \mathrm{g} / \mathrm{ml}$ was used as reference. Absorbance measurements were taken at $540 \mathrm{~nm}$. Data for percent inhibition of haemolysis are presented as mean \pm SEM of $n=4$. 


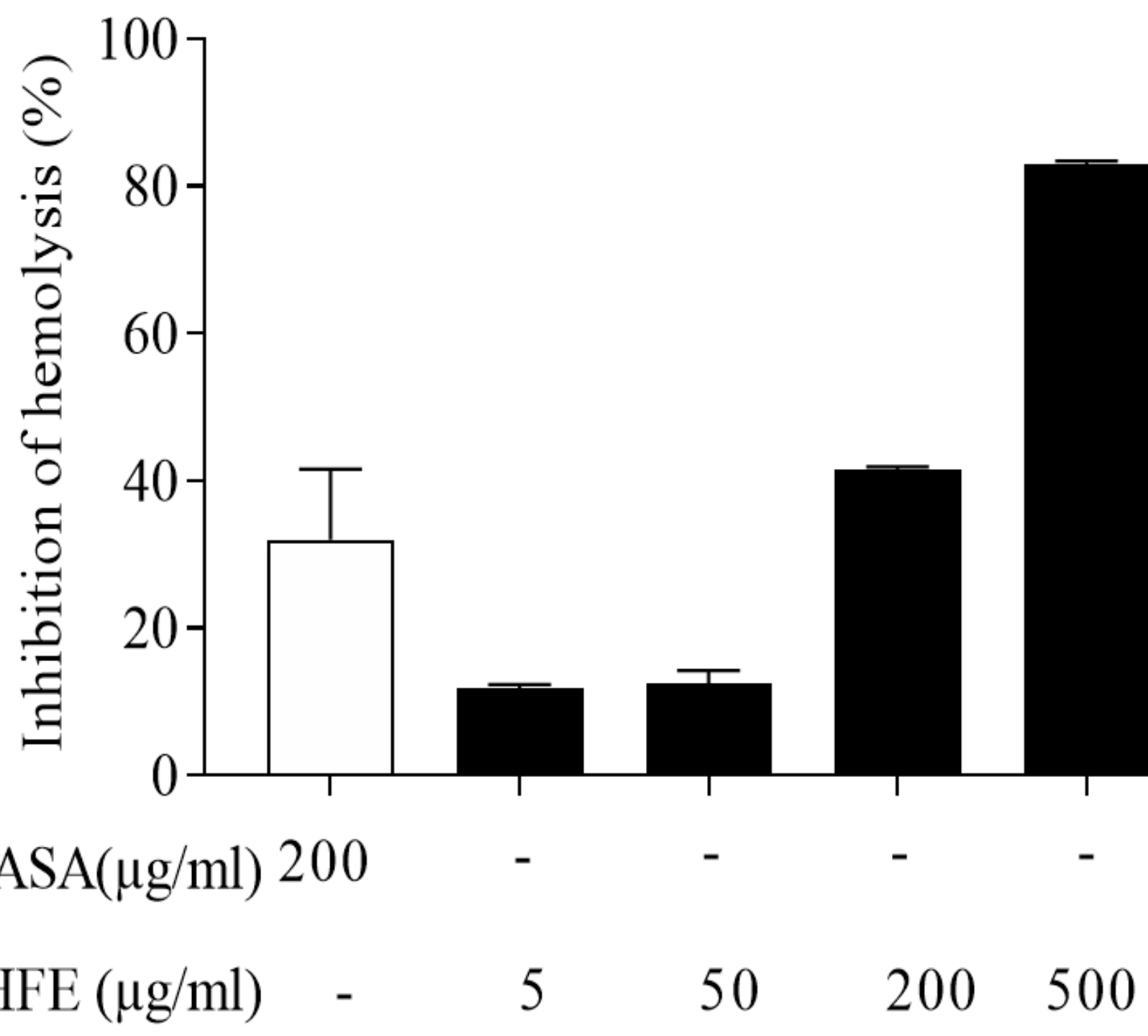

Figure 4

Whole blood was collected from rats under anaesthesia, washed and reconstituted as a $40 \% \mathrm{v} / \mathrm{v}$ red blood cell suspension. Red blood cell suspensions were incubated with $\operatorname{HFE}(5,50,200$ or $500 \mu \mathrm{g} / \mathrm{ml})$. Acetyl salicylic acid (ASA) $200 \mu \mathrm{g} / \mathrm{ml}$ was used as reference. Absorbance measurements were taken at $540 \mathrm{~nm}$. Data for percent inhibition of haemolysis are presented as mean \pm SEM of $n=4$. 
A

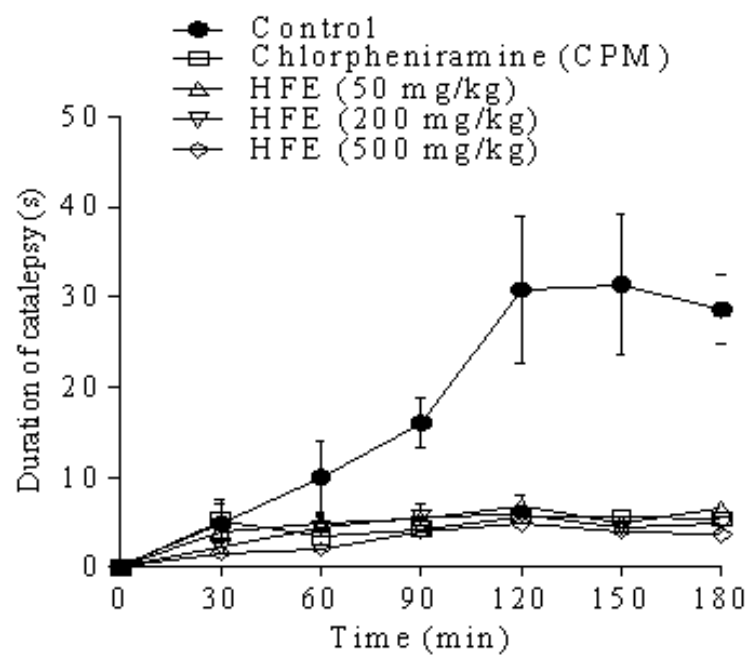

C

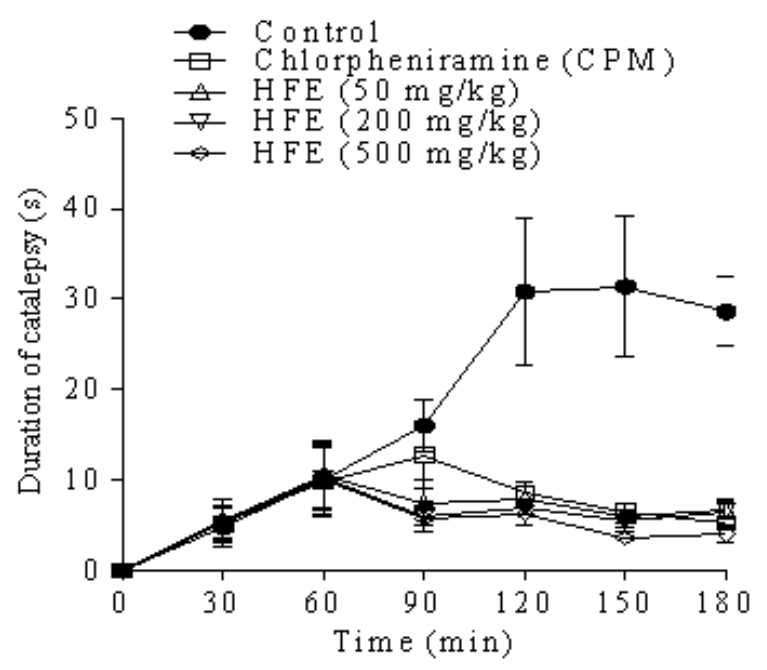

B

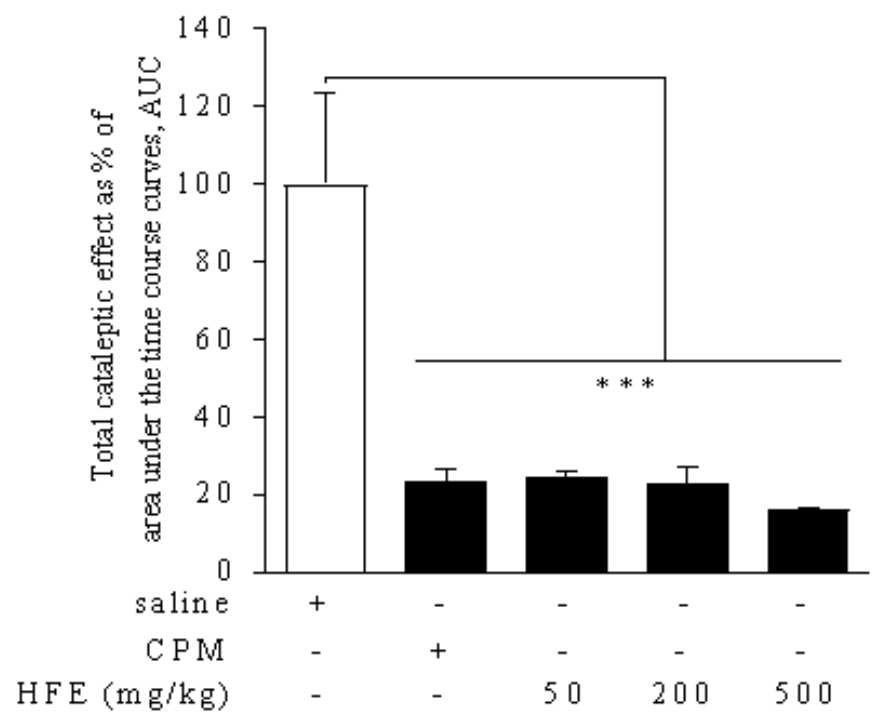

D

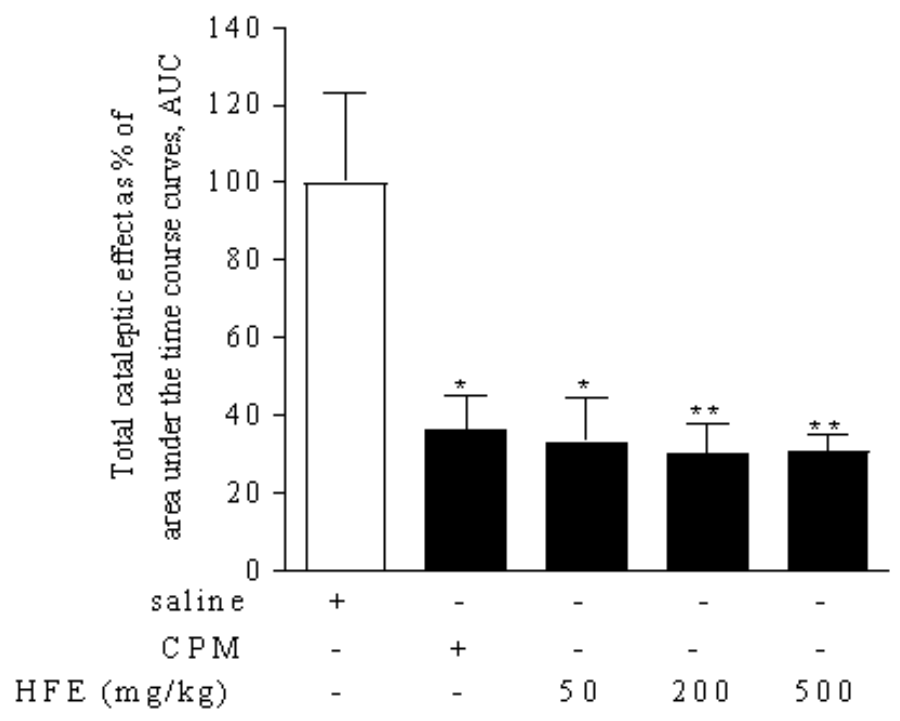

Figure 5

ICR mice received saline $10 \mathrm{ml} / \mathrm{kg}$, chlorpheniramine (CPM) $4 \mathrm{mg} / \mathrm{kg}$ or HFE 50-500 mg/kg prophylactic $(A, B)$ or therapeutic (C, D). Total catalepsy was calculated as area under the time course curves (right panel). Data were analysed by one-way ANOVA followed Dunnet's post hoc test, and are presented as mean \pm SEM of $n=6$. Indications of significance are relative to the saline-treated control. ${ }^{\star} P<0.05,{ }^{\star *} P<$ $0.01,{ }^{*} * \mathrm{P}<0.001$, ns is not significant. 
A

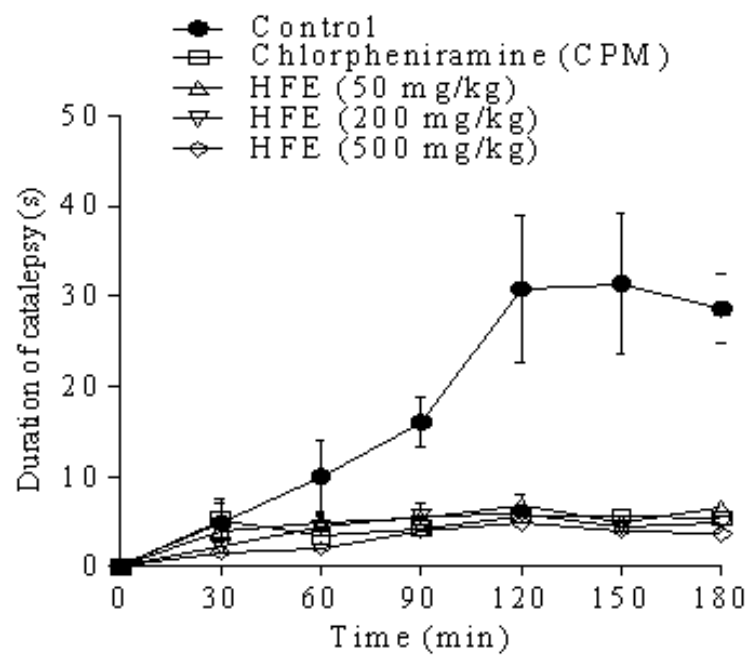

C

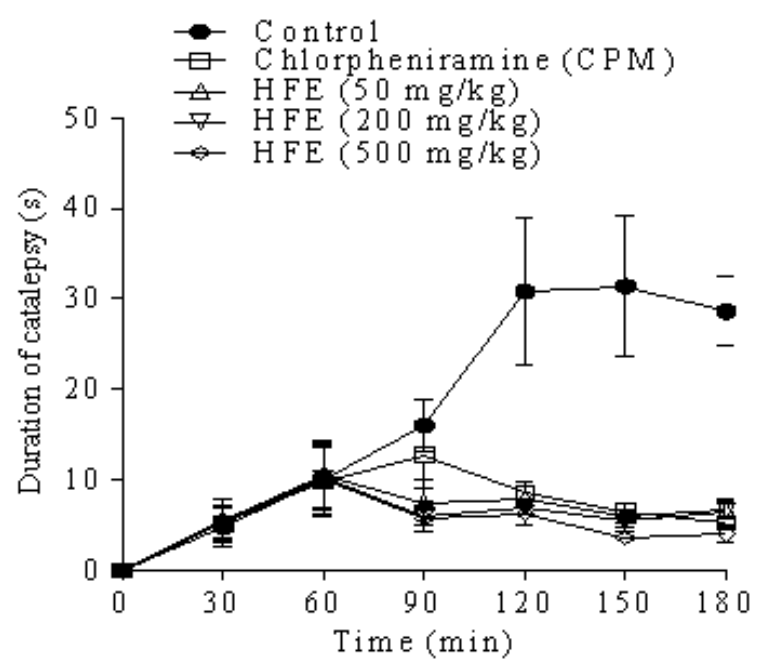

B

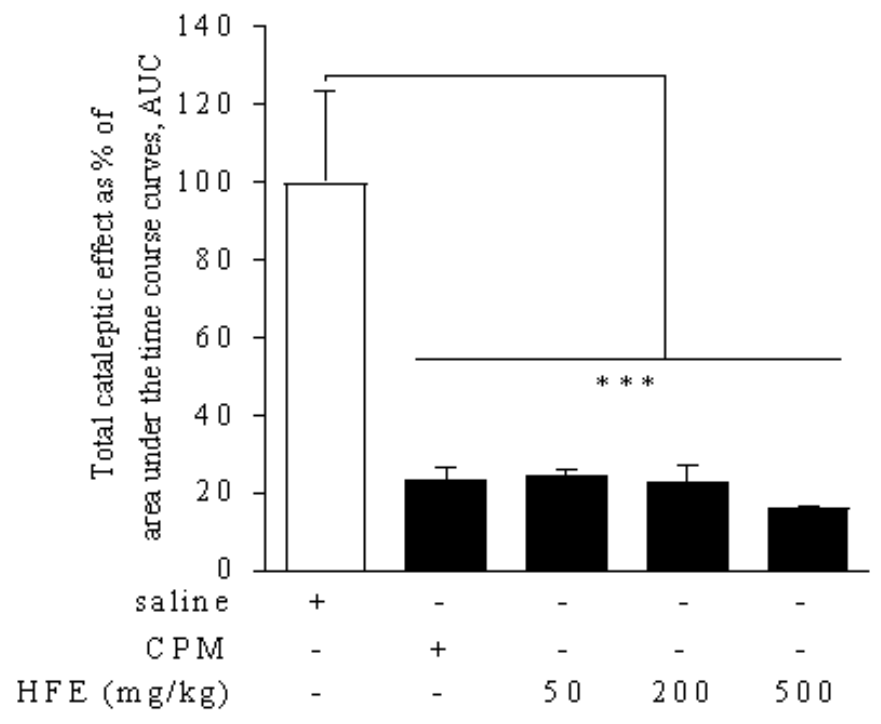

D

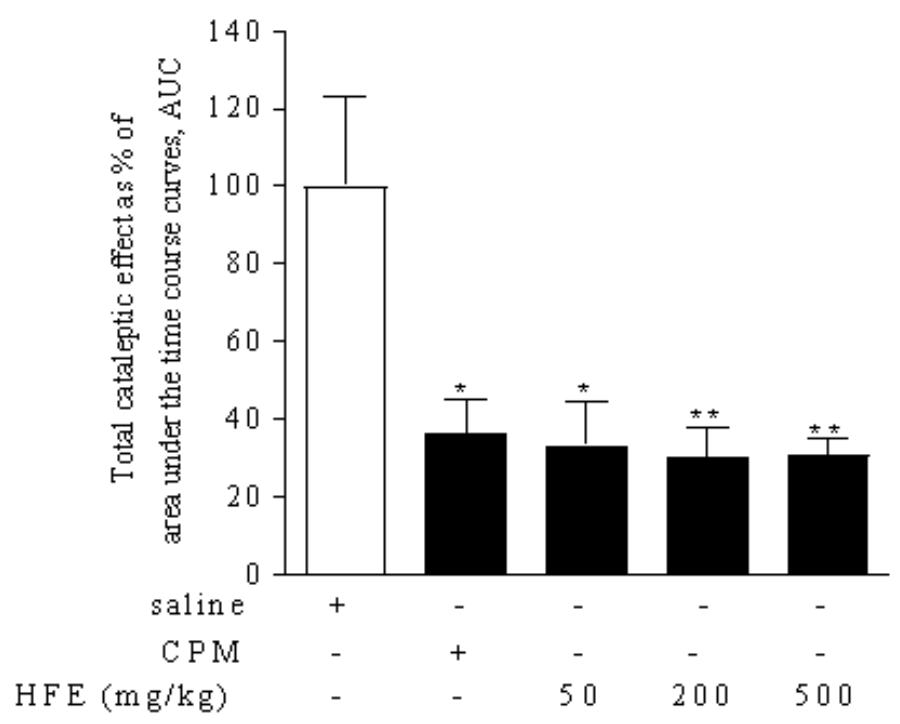

\section{Figure 5}

ICR mice received saline $10 \mathrm{ml} / \mathrm{kg}$, chlorpheniramine (CPM) $4 \mathrm{mg} / \mathrm{kg}$ or HFE 50-500 mg/kg prophylactic $(A, B)$ or therapeutic (C, D). Total catalepsy was calculated as area under the time course curves (right panel). Data were analysed by one-way ANOVA followed Dunnet's post hoc test, and are presented as mean \pm SEM of $n=6$. Indications of significance are relative to the saline-treated control. ${ }^{*} P<0.05,{ }^{*} \mathrm{P}<$ $0.01, * \star \star P<0.001$, ns is not significant. 


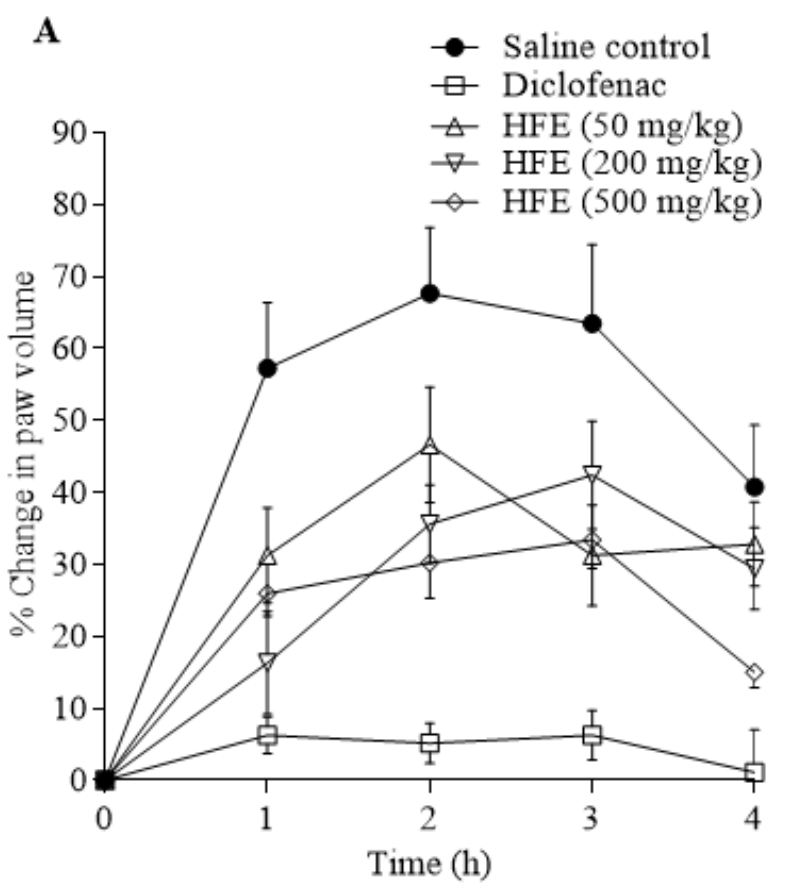

B

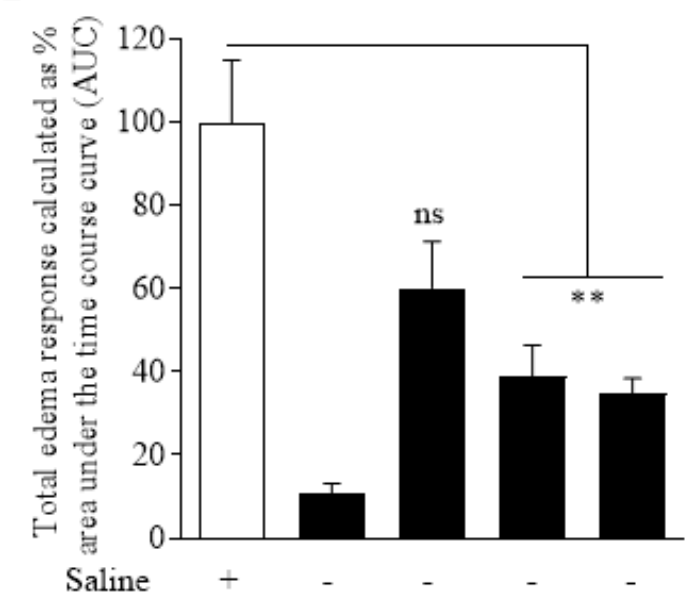

Diclofenac

$\mathrm{HFE}(\mathrm{mg} / \mathrm{kg})$
C

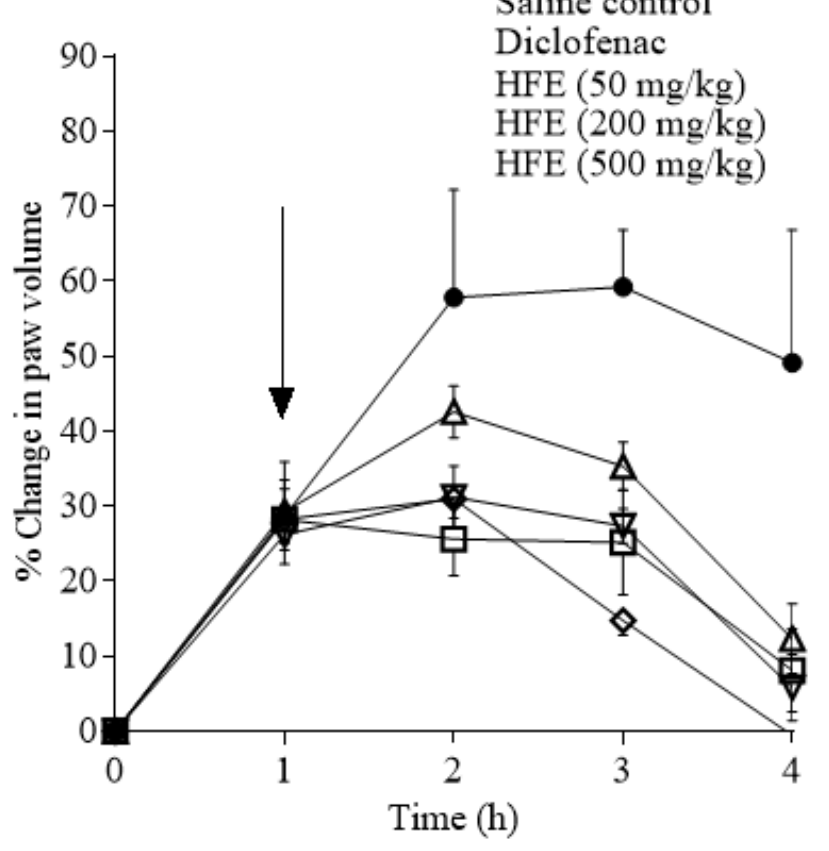

D

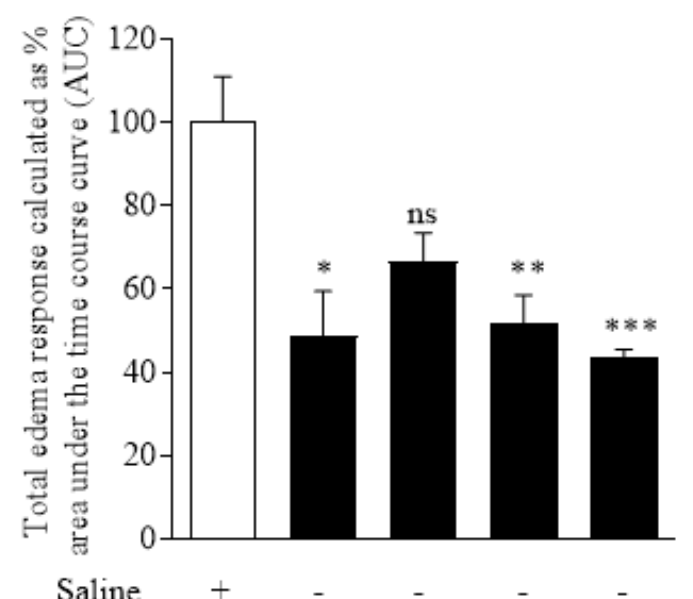

Diclofenac

$\mathrm{HFE}(\mathrm{mg} / \mathrm{kg}) \quad-\quad-\quad 50 \quad 200 \quad 500$

Figure 6

ICR mice received saline $10 \mathrm{ml} / \mathrm{kg}$, diclofenac $4 \mathrm{mg} / \mathrm{kg}$ or HFE $50-500 \mathrm{mg} / \mathrm{kg}$ prophylactic (left panel) or therapeutic (right panel). Total oedema was calculated as area under the time course curves (B and D). Data are presented as mean \pm S.E.M for $n=6$. Arrow indicates point of extract administration in the therapeutic protocol. Indications of significance are relative to the saline-treated control. ${ }^{*} P<0.05,{ }^{*} \mathrm{P}<$ 0.01 , ${ }^{* \star *} \mathrm{P}<0.001$. 


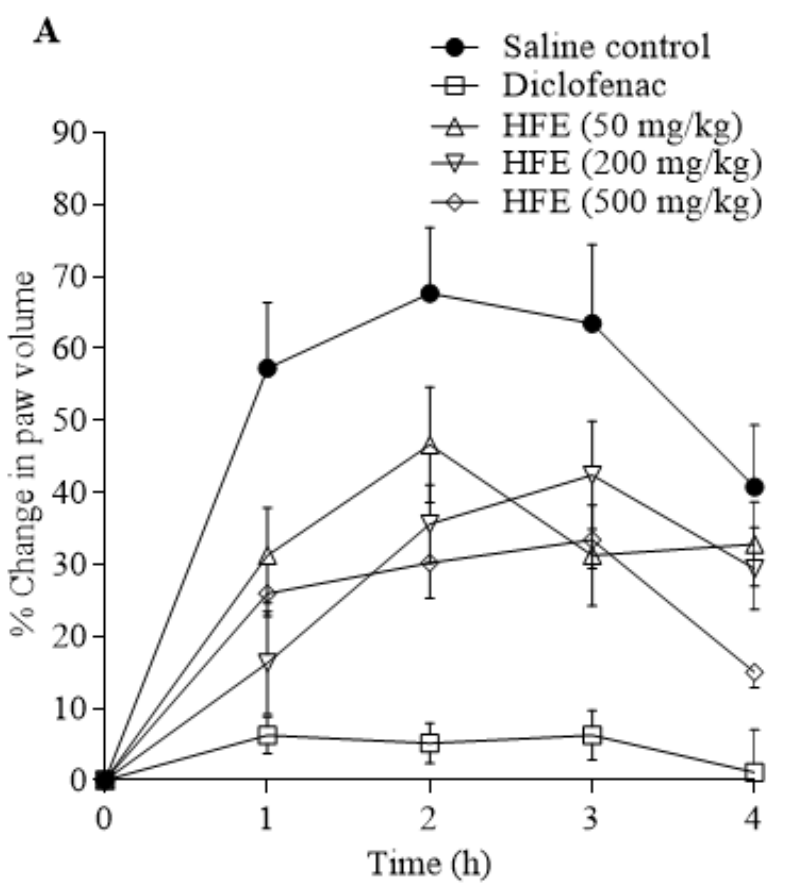

B

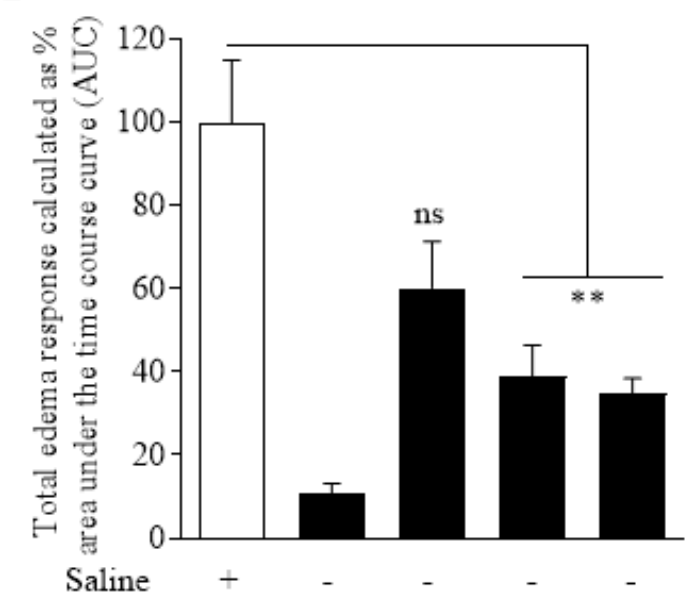

Diclofenac

$\mathrm{HFE}(\mathrm{mg} / \mathrm{kg})$
C

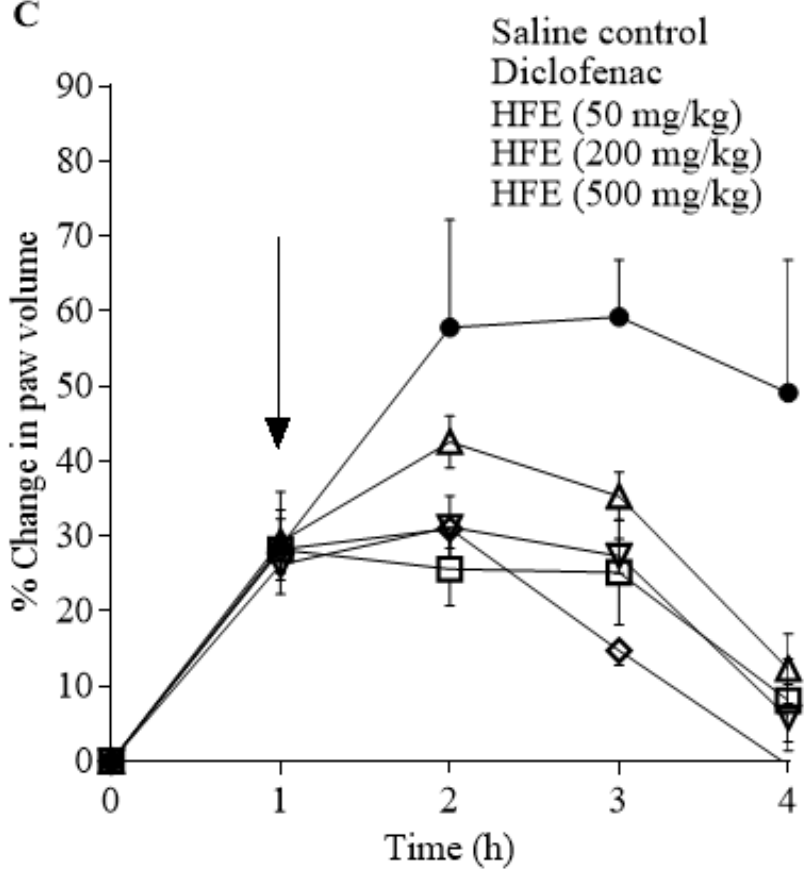

D

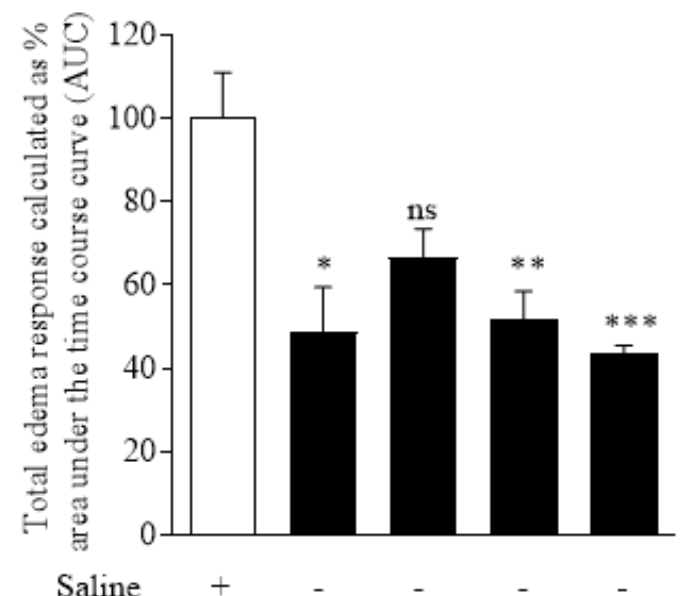

Diclofenac

$\mathrm{HFE}(\mathrm{mg} / \mathrm{kg}) \quad-\quad-\quad 50 \quad 200 \quad 500$

Figure 6

ICR mice received saline $10 \mathrm{ml} / \mathrm{kg}$, diclofenac $4 \mathrm{mg} / \mathrm{kg}$ or HFE $50-500 \mathrm{mg} / \mathrm{kg}$ prophylactic (left panel) or therapeutic (right panel). Total oedema was calculated as area under the time course curves (B and $D)$. Data are presented as mean \pm S.E.M for $n=6$. Arrow indicates point of extract administration in the therapeutic protocol. Indications of significance are relative to the saline-treated control. ${ }^{*} P<0.05,{ }^{*} \mathrm{P}<$ 0.01 , ${ }^{* \star *} \mathrm{P}<0.001$. 
A

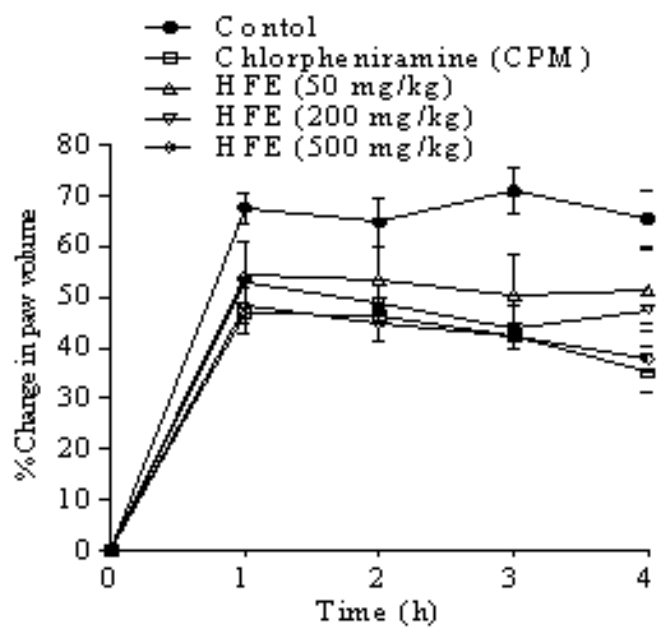

C

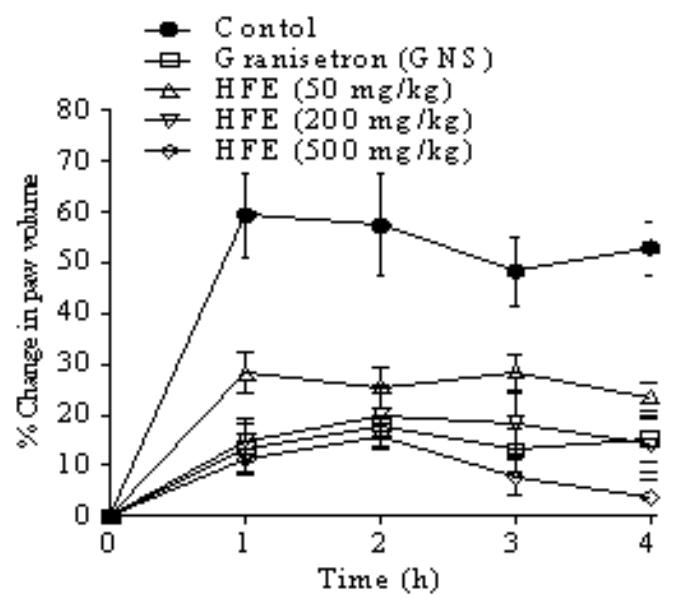

E

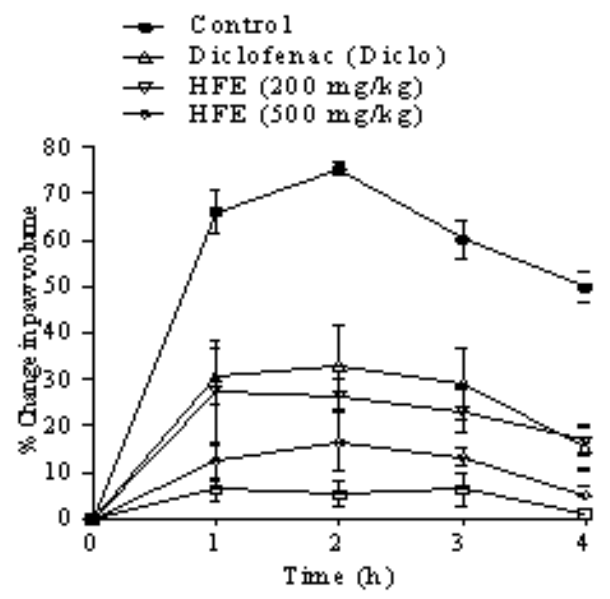

B

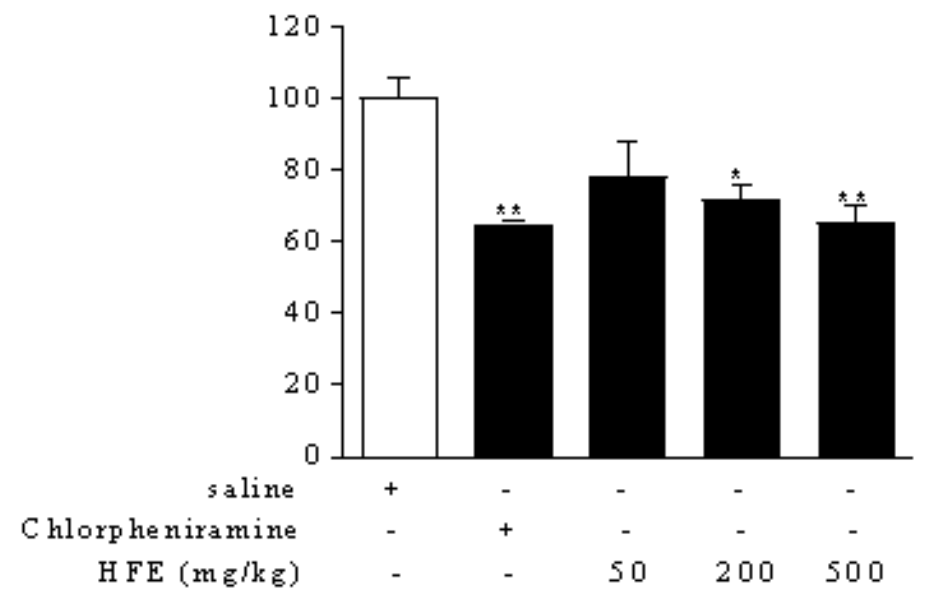

D

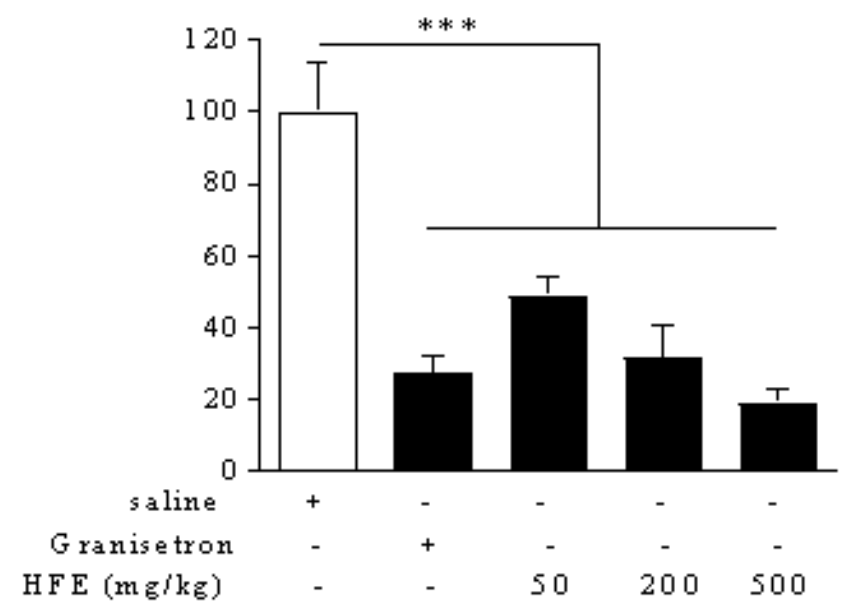

F

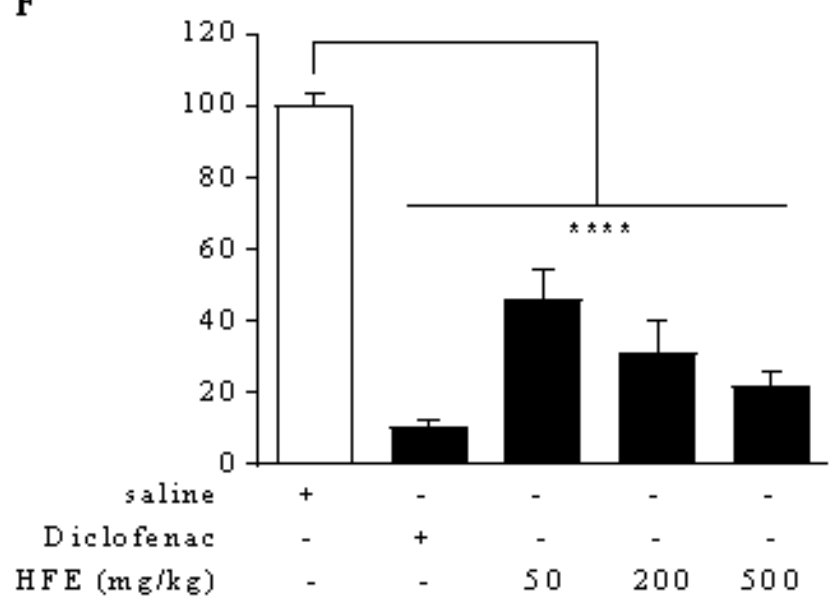

Figure 7

Mice received normal saline $1 \mathrm{ml} / \mathrm{kg}$, chlorpheniramine $10 \mathrm{mg} / \mathrm{kg}$, granisetron $100 \mu \mathrm{g} / \mathrm{kg}$, diclofenac 0.93 mg kg or HFE 50-500 mg kg p.o. Total oedema was calculated as area under the time course curves (right panels). Data are presented as mean \pm S.E.M of $n=6$. Indications of significance are relative to the saline-treated control. ${ }^{\star} \mathrm{P}<0.05,{ }^{*} \mathrm{P}<0.01,{ }^{\star *} \mathrm{P}<0.001,{ }^{\star} * \star \star \mathrm{P}<0.0001$. 
A

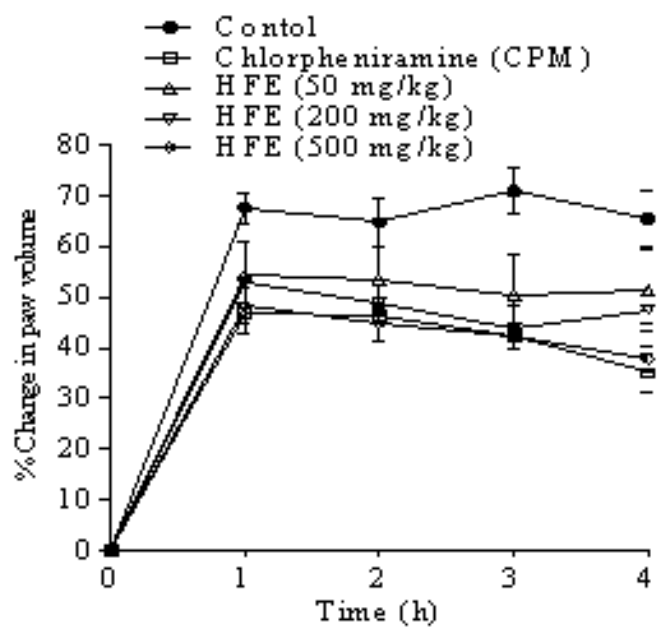

C

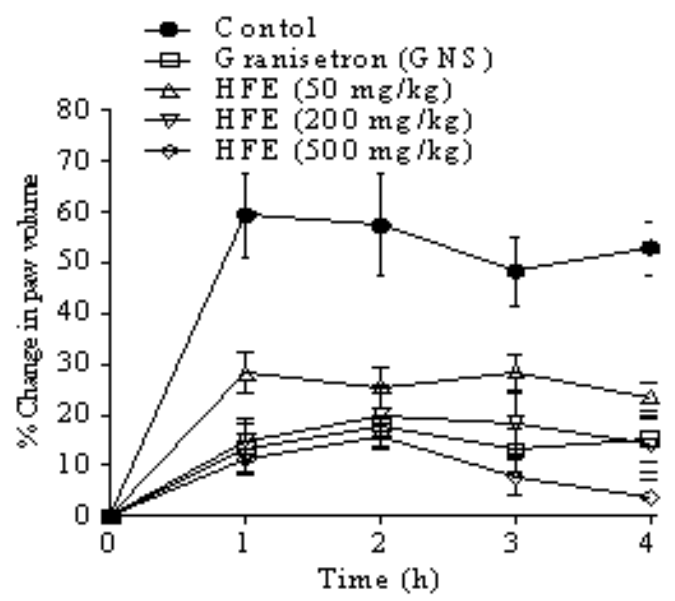

E

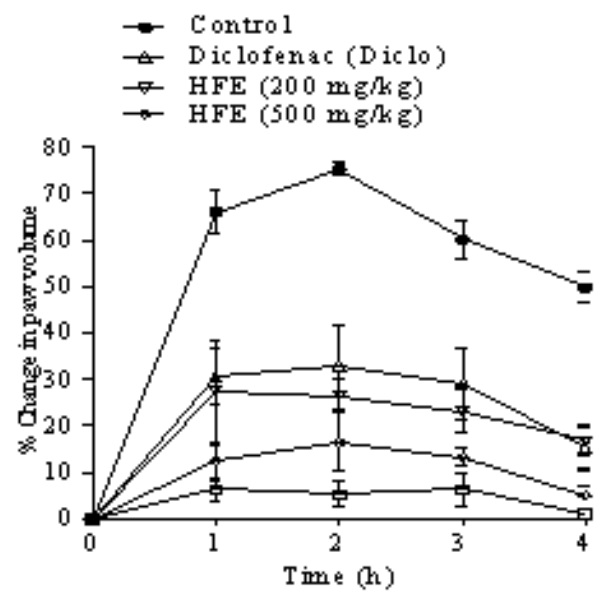

B

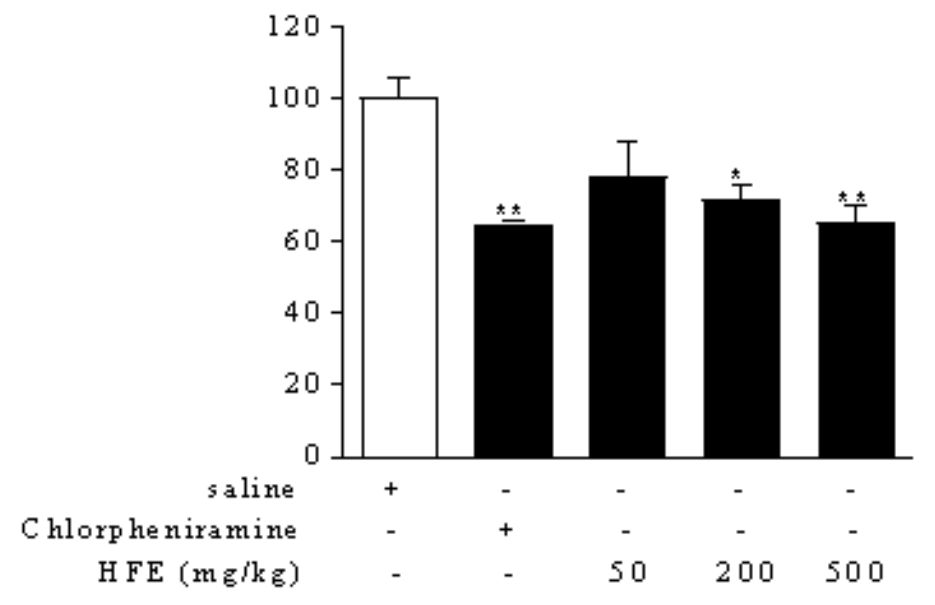

D

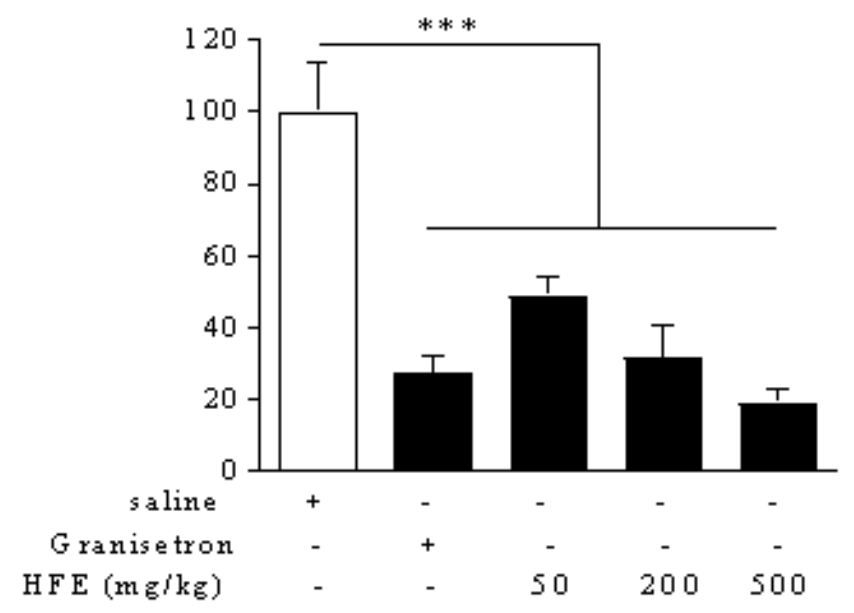

F

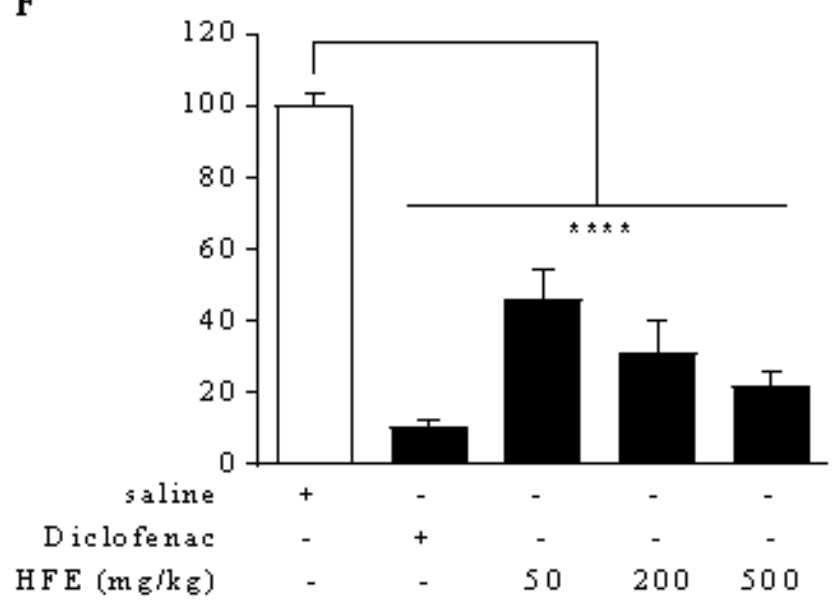

Figure 7

Mice received normal saline $1 \mathrm{ml} / \mathrm{kg}$, chlorpheniramine $10 \mathrm{mg} / \mathrm{kg}$, granisetron $100 \mu \mathrm{g} / \mathrm{kg}$, diclofenac 0.93 mg kg or HFE 50-500 mg kg p.o. Total oedema was calculated as area under the time course curves (right panels). Data are presented as mean \pm S.E.M of $n=6$. Indications of significance are relative to the saline-treated control. ${ }^{\star} P<0.05, * \star P<0.01, * \star \star P<0.001, \star \star \star \star * P<0.0001$. 